\title{
DESMIDIOFLÓRULA DE UM LAGO DA PLANÍCIE DE INUNDAÇÃO DO RIO ACRE, ESTADO DO AMAZONAS, BRASIL.
}

\author{
Maria Rosélia Marques LOPES ${ }^{1}$, Carlos Eduardo de Mattos BICUDO ${ }^{2}$
}

\begin{abstract}
RESUMO - Este trabalho trata da desmidioflórula de um lago marginal do rio Acre, lago Novo Andirá (AM), baseado na análise de 52 amostras coletadas, mensalmente, no período de maio/ 1988 a junho/1989. Foram identificados e descritos 98 táxons de desmídias, dos quais 38 são variações da espécie típica correspondente, distribuídos em 10 gêneros e três famílias. Os gêneros Cosmarium, Closterium e Staurastrum foram, em termos qualitativos, os mais bem representados, com 29, 19 e 16 espécies, respectivamente; os menos representados foram Gonatozygon, Octacanthium e Xanthidium, com uma espécie cada. A distribuição geográfica foi feita com base na literatura publicadada até dezembro de 1998 e foram considerados tanto os trabalhos mais completos, com descrições e/ou ilustrações, quanto aqueles nos quais constam apenas listagem de espécies. Devido à variação morfológica observada na população, particularmente neste trabalho, o gênero Staurastrum foi o que apresentou maiores problemas taxonômicos, conflitando dados registrados em literatura. A variação morfológica em nível populacional também impossibilitou a identificação de Euastrum verrucosum Ehrenberg ex Ralfs.
\end{abstract}

Palavras-chave: Desmídias, Lago Amazônico, Taxonomia.

\section{Desmid Flora of the Flood Plain Lake, Acre River, Amazonas State, Brazil.}

\begin{abstract}
This paper presents a taxonomic survey of the desmid flora of a marginal oxbowl lake on the River Acre - Lago Novo Andirá (AM), northern Brazil. The study is based on 52 samples collected over 13 consecutive months (May 1988 to June 1989). Ninety-eight taxa of desmids were identified and described, classified in 10 genera and 3 families. Of the 98 taxa, 38 are variation of the corresponding typical forma. The genera Cosmarium, Closterium and Staurastrum were qualitatively the best-represented in the lake, with 29, 19, and 16 species respectively. The least represented were Gonatozygon, Octacanthium, and Xanthidium, each one with a single species. Geographical distribution was based on all data in the literature published up to December 1998 including publications in which there are morphological descriptions and/ or illustrations of the algae, as well as those in which mere check lists were considered. Taxonomic problems involved were directly related to the morphological variation observed within the populations, and the genera Staurastrum displayed the greatest number of taxonomic difficulties in conflict with data in the literature. Morphological variation observed at population level made the infraspecific identification of Euastrum verrucosum Ehrenberg ex Ralfs impossible.
\end{abstract}

Key-words: Desmids, Amazonian Lake, Taxonomy.

\section{INTRODUÇÃO}

Os inúmeros ecossistemas aquáticos presentes na região Amazônica, exemplificados por rios, lagos, igarapés, paranás, igapós e grandes e pequenas represas constituem o maior contingente aquático do mundo, onde se encontra presente uma flórula de microalgas

${ }^{1}$ Universidade Federal do Acre, Departamento de Ciências da Natureza, 69915-900, Rio Branco, AC, Brasil; e-mail: roselia@ufac.br

${ }^{2}$ Instituto de Botânica, Seção de Ficologia,01061-970, São Paulo, SP, Brasil; e-mail: cbicudo@terra.com.br 
exuberante, porém, ainda muito pouco conhecida. Particularmente para o estado do Amazonas, em 160 anos de estudos, existem raros trabalhos sobre a taxonomia do fitoplâncton, os quais são, em sua maioria, listagens de espécies de ambientes demasiadamente restritos.

Estudos ficológicos com abordagem taxonômica no estado do Amazonas tiveram início com o trabalho de Ehrenberg (1841), reeditado em 1843. Tais estudos foram exclusividade de pesquisadores estrangeiros por muitas décadas. Constam, entre eles, os seguintes: Dickie (1881), Möbius (1892), Zimmermann (1913, 1914), Gessner \& Kolbe (1934), Drouet (1938), Kammerer (1938), Hustedt (1952a, 1952b), Sioli (1968), Karling (1944), Thomasson (1955, 1971, 1977), Förster (1963, 1964, 1974), Scott et al. (1965), Schmidt \& Uherkovich (1973), Schmidt (1973), Uherkovich \& Schmidt (1974), Uherkovich (1976, 1981), Uherkovich \& Rai (1979), Uherkovich \& Franken (1980), Cronberg (1989), Palamar-Mordvintseva \& Tsarenko (1990) e Conforti (1993a, 1993b, 1994).

A participação de pesquisadores brasileiros em estudos taxonômicos de algas do estado do Amazonas iniciou-se com os trabalhos de Martins (1980a, 1980b, 1982, 1986a, 1986b). Seguiram-se os de Sant'Anna \& Martins (1982), Bicudo (1986), Fukushima \& Xavier (1988), Bittencourt-Oliveira (1990, 1993a, 1993b, 1993c, 1994, 1995, 1997), Menezes et al. (1995), Necchi-Júnior \& Zuchi (1995) e Sophia \& Dias (1996).

O presente trabalho constitui mais uma contribuição ao estudo taxonômico da flórula de algas do estado do Amazonas, no qual são descritas e ilustradas 98 espécies de desmídias (Desmidiales, Zygnemaphyceae).

\section{MATERIAL E MÉTODOS}

O lago Novo Andirá é um lago da planície de inundação do rio Acre, de água branca (Sioli, 1968) e localiza-se no seringal Novo Andirá ( $\left.67^{\circ} 30^{\prime} \mathrm{W}, 9^{\circ} 30^{\prime} \mathrm{S}\right)$, estado do Amazonas, Brasil (Fig. 1).

Foram analisadas 52 amostras coletadas mensalmente, com rede de plâncton, no período de maio de 1988 a junho de 1989 , as quais encontram-se fixadas e preservadas em Solução de Transeau (Bicudo \& Bicudo, 1970) e depositadas no Herbário Científico do Estado "Maria Eneyda P. Kauffman Fidalgo", do Instituto de Botânica da Secretaria do Meio Ambiente do Estado de São Paulo.

Para cada espécie, variedade ou forma taxonômica identificada são fornecidas breves descrições, medidas celulares, ilustrações da vista frontal e, sempre que possível, também das vistas apical e lateral, citação da referência bibliográfica que contém a descrição e/ou diagnose original do táxon, relação do material examinado, Distribuição geográfica no estado do Amazonas e, quando necessário, comentários.

As formas das células foram padronizadas segundo Stearn (1983), tanto no material ora examinado quanto na adequação das formas utilizadas de outros trabalhos científicos.

Adotou-se o sistema de classificação de Mix (1972) para a classe Zygnemaphyceae (= Conjugatophyceae ou Zygophyceae) e a identificação taxonômica dos espécimes foi, em nível de gênero, primeiro providenciada conforme Bourrelly (1972). Para as categorias infragenéricas, foi utilizada bibliografia mais especializada, dando-se especial ênfase aos trabalhos de flora, monografia e revisão.

Em Desmidiaceae, foi considerada incisão mediana profunda aquela em cujos indivíduos o istmo tem largura igual ou menor do que a metade da largura total da semicélula, sem considerar os processos quando existentes; e incisão mediana rasa quando o istmo tem largura maior do que a metade da largura total da semicélula. Largura celular também foi utilizada para definir a proporção do comprimento dos processos, quando estes se apresentaram. Assim, foram considerados longos os processos cujo comprimento foi, proporcionalmente, maior do que a largura da semicélula; e curtos aqueles cujo comprimento foi menor ou igual à largura da semicélula.

No gênero Closterium, a forma do ápice celular foi padronizada segundo Coesel (1983) e Castro (1987), e o grau de curvatura foi medido através do closteriocurvímetro (Heimans, 1946). 


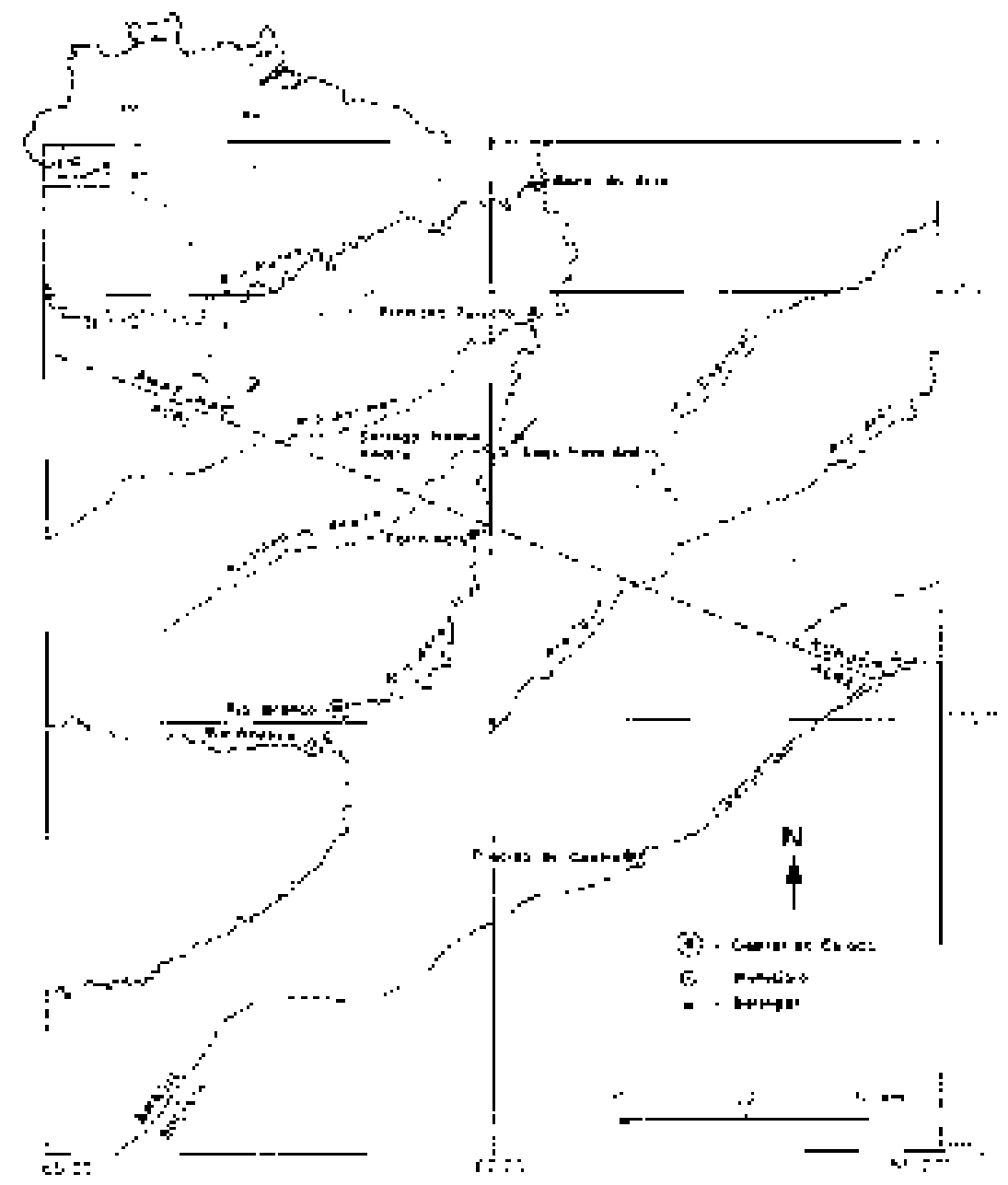

Figura 1 - Mapa de localização do lago Novo Andirá, estado do Amazonas, Brasil.

\section{RESULTADOS E DISCUSSÃO}

Foram identificados 98 táxons em nível infragenérico, classificados em 10 gêneros (Closterium, Cosmarium, Euastrum, Gonatozygon, Micrasterias, Octacanthium, Pleurotaenium, Staurastrum, Staurodesmus, Xanthidium) e distribuídos nas famílias Desmidiaceae (78), Closteriaceae (19), Gonatozygaceae (1). Das 98 espécies, 38 são variações das espécies típicas correspondentes.

Uma espécie de Staurodesmus não foi identificada em nível infragenérico devido à ausência de zigósporos. Duas espécies de Cosmarium (Cosmarium sp. 1 e Cosmarium sp. 2) e uma variedade de Euastrum verrucosum Ehrenberg ex Ralfs var., não puderam ser identificadas por contar com número insuficiente de exemplares para definir se se trata, ao que tudo indica, de espécies e variedade novas, respectivamente.

Entre as espécies e respectivas variedades e formas taxonômicas identificadas, 55 constituem primeira citação para o estado do Amazonas.

O gênero Cosmarium (Desmidiaceae) foi o mais bem representado no lago, caso se 
considere o número de táxons, com 29 táxons (dois em nível gênero, 27 em nível infragenérico, incluindo oito variedades e uma forma taxonômica não típicas), que equivaleram a $29,6 \%$ do total de táxons identificados.

Não foram encontrados representantes de hábito filamentoso (exemplos: Bambusina, Desmidium, Hyalotheca), nem colonial (exemplo: Cosmocladium).

\section{Família GONATOZYGACEAE}

\section{Gonatozygon De Bary}

Gonatozygon pilosum Wolle var. pilosum Bull. Torrey Bot. Club, 9(1): 27, pl. 13, fig. 16. 1882. (Fig. 2).

Célula 9-16 vezes mais comprida que larga (140-295 x 14-18 $\mu \mathrm{m})$ cloroplastídio laminar, axial, 1 por semicélula, pirenóides 6-7.

Distribuição geográfica no estado do Amazonas: rio Negro (Uherkovich 1976); rio Jaú (Uherkovich \& Rai 1979).

Material examinado: SP239184, SP239198, SP239202, SP239215, SP239216, SP239218, SP239219, SP239220, SP239221 e SP239222.

\section{Família CLOSTERIACEAE}

Closterium Nitzsch

Chave artificial para identificação das espécies e variedades de Closterium

1. Célula reta ou ligeiramente curvada.

2. Célula reta.

3. Célula maior que $100 \mu \mathrm{m}$ compr C. closterioides var. closterioides

3. Célula menor que $100 \mu \mathrm{m}$ compr. C. navicula var. navicula

2. Célula ligeiramente curvada.

4. Indivíduo com processos setáceos.

5. Processos aprox. 1/5 do compr. total da célula C. rostratum var. rostratum

5. Processos aprox. 1/3 do compr. total da célula C. kuetzingii var. kuetzingii

4. Indivíduo sem processos setáceos.

6. Célula maior que $250 \mu \mathrm{m}$ compr.

7. Região mediana inflada C. lunula var. biconvexum

7. Região mediana da célula retilínea ou quase.

8. Pirenóides espalhados no cloroplastídio ................ C. turgidum var. giganteum mediana.

8. Pirenóides arranjados em série

9. Célula 10,8-11,9 vezes mais comprida que larga ............... . baillyanum var. baillyanum

9. Célula 21,6-22,8 vezes mais comprida que larga

C. lineatum var. lineatum

6. Célula menor que $250 \mu \mathrm{m}$ compr.

10. Célula inflada na região mediana C. tumidum var. tumidum

10. Célula não inflada na região mediana C. acutum var. acutum

1. Célula lunada, sigmóide, fortemente curvada.

11. Indivíduo maior que $140 \mu \mathrm{m}$ compr.

12. Relação comprimento:largura celular maior que 8 .

13. Ápices oblíqüo-truncados; parede celular lisa,

incolor

C. dianae var. arcuatum

13. Ápices arredondados, espessamento em forma de anel;

parede celular estriada, acastanhada C. nematodes var. nematodes

12. Relação comprimento:largura celular menor que 8 .

14. Pirenóides espalhados no cloroplastídio ............. C. ehrenbergii var. ehrenbergii

14. Pirenóides arranjados em série mediana no cloroplastídio.

15. Ápices celulares arredondados . $C$ moniliferum var. moniliferum

15. Ápices celulares cônico-truncados C. moniliferum var. nasutum

11. Indivíduo menor que $140 \mu \mathrm{m}$ compr.

16. Célula sigmóide C. tortum

16. Célula lunada.

17. Ápices celulares acuminados C. incurvum var. incurvum

17. Ápices celulares oblíqüo-truncados.

18. Célula levemente inflada na região mediana C. dianae var. brevius

18. Célula não inflada na região mediana C. dianae var. minus

Closterium closterioides (Ralfs) Louis \& Peeters var. closterioides Bull. Jard. bot. natn. Belg., 37(4): 410, pl. 18, fig. 119. 1967. (Fig. 3).

Célula reta, elíptica a fusiforme, 3,4-4,7 vezes mais comprida que larga (155-186 x 38$45 \mu \mathrm{m})$, cloroplastídio axial, cristas 4-5, 
pirenóides 3-5 em série mediana.

Distribuição geográfica no estado do Amazonas: rio Negro (Uherkovich 1976) como Closterium libellula Focke ex Nordstedt var. interruptum (West \& West) Krieger; Nhamundá e Terra Santa (Thomasson 1977), rio Madeira (Uherkovich 1981) como Closterium libellula Focke.

Material examinado: SP239181, SP239184.

Closterium navicula (Brébisson) Lütkemüller var. navicula Beitr. Biol. Pfl. Breslau, 8(3): 395, 405, 408. 1902. (Fig. 4).

Célula reta, 3,3-4 vezes mais comprida que larga $(62-72 \times 15-18 \mu \mathrm{m})$, cloroplastídio axial, cristas 4-6, pirenóides 1-2 em série mediana.

Distribuição geográfica no estado do Amazonas: rio Uaupés (Scott et al. 1965), rio Abacaxis, rio Canumã (Förster 1974), igarapé Acará, igarapé Barro Branco, Reserva Ducke, estrada Manaus-Itacoatiara, $\mathrm{km} 45$ (Uherkovich \& Franken 1980), rio Maués-mirim (Uherkovich (1981). SP239184

Material examinado: SP239181,

Closterium tortum Griffiths J. Linn. Soc. Bot. Lond., 47: 89, pl. 1, fig. 4-6. 1925. (Fig. 5).

Célula curvada a sigmóide, curvatura irregular, 11,5-12,5 vezes mais comprida que larga (81-94 x 7-7,5 $\mu \mathrm{m})$, cloroplastídio axial, pirenóides 5-9 em série mediana; vacúolo terminal, corpúsculo trepidante 1 .

Distribuição geográfica no estado do Amazonas: lago Novo Andirá ( primeira citação da ocorrência da espécie).

Material examinado: SP239184, SP239219, SP239220.

Closterium incurvum Brébisson var. incurvum Mem. Soc. Imp. Sci. nat. Cherbourg, 4: 150, pl. 2, fig. 47. 1856 . (Fig. 6-7).

Célula curvada (160-180 de arco), 5,310 vezes mais comprida que larga (43-70 x 8$10 \mu \mathrm{m}$ ), cloroplastídio axial, pirenóides 1-2; vacúolo terminal; corpúsculo trepidante 1 .

Distribuição geográfica no estado do Amazonas: rio Unini (Uherkovich \& Rai 1979) como Closterium venus Kützing ex Ralfs var. incurvum (Brébisson) Krieger.

Material examinado: SP239181, SP239182, SP239183, SP239184, SP239185, SP239189, SP239194, SP239221.

Closterium tumidum Johnson var. tumidum Bull. Torrey bot. Club, 22(7): 291, pl. 239, fig. 4. 1895. (Fig. 8-9).

Célula curvada (40-60 de arco), 5,2-9,4 vezes mais comprida que larga (78-180 x 14$20 \mu \mathrm{m})$, cloroplastídio axial, cristas 3-4, pirenóides 3-5 em série mediana.

Distribuição geográfica no estado do Amazonas: lago Novo Andirá (primeira citação da ocorrência da espécie).

Material examinado: SP239181, SP239184, SP239198, SP239201, SP239210, SP239211.

Closterium acutum Brébisson var. acutum Brit. Desm. 177, pl. 30, fig. 5a-f. 1848. (Fig. 10).

Célula curvada ( $40^{\circ}$ de arco), 15-16,4 vezes mais comprida que larga (73-82 x 4,5$5 \mu \mathrm{m})$, cloroplastídio axial, pirenóides 4-5 em série mediana, vacúolo terminal.

Distribuição geográfica no estado do Amazonas: lago Rio Preto da Eva (Thomasson 1971), igarapé Barro Branco (Uherkovich \& Franken 1980). SP239222.

Material examinado: SP239181,

Closterium dianae Ehrenberg ex Ralfs var. arcuatum (Brébisson) Rabenhorst Fl. Eur. algar., 3: 133. 1868. (Fig. 11-12).

Célula curvada (140-150 ${ }^{\circ}$ de arco), $12,5-$ 14,5 vezes mais comprida que larga (250-320 x 20-22 $\mu \mathrm{m}$ ), cloroplastídio axial, pirenóides 45 em série mediana; vacúolo terminal, corpúsculo trepidante 1.

Distribuição geográfica no estado do Amazonas: lago Novo Andirá (primeira citação da ocorrência da variedade).

Material examinado: SP239181.

Closterium dianae Ehrenberg ex Ralfs var. minus Hieronymus In Engler, Pflanzenw. Öst-Afrikas, 1(B): 19. 1895. (Fig. 13-14).

Célula curvada (120-140 ${ }^{\circ}$ de arco), 6,813,6 vezes mais comprida que larga (90-140 x 8-18 $\mu \mathrm{m})$, cloroplastídio axial, pirenóides 4-5 em série mediana; vacúolo terminal.

Distribuição geográfica no estado do Amazonas: igarapé Jibóia, estrada ManausItacoatiara, km 45 (Uherkovich \& Franken 1980).

Material examinado: SP239181, SP239184, SP239198, SP239201.

Closterium dianae Ehrenberg ex Ralfs var. brevius (Petkov) Krieger In Rabenhorst, Kryptogamen-Fl. Deutschl., 13(1): 296, pl. 19, fig. 13. 1937. (Fig. 15).

Célula curvada (130-140 de arco), 5,7- 

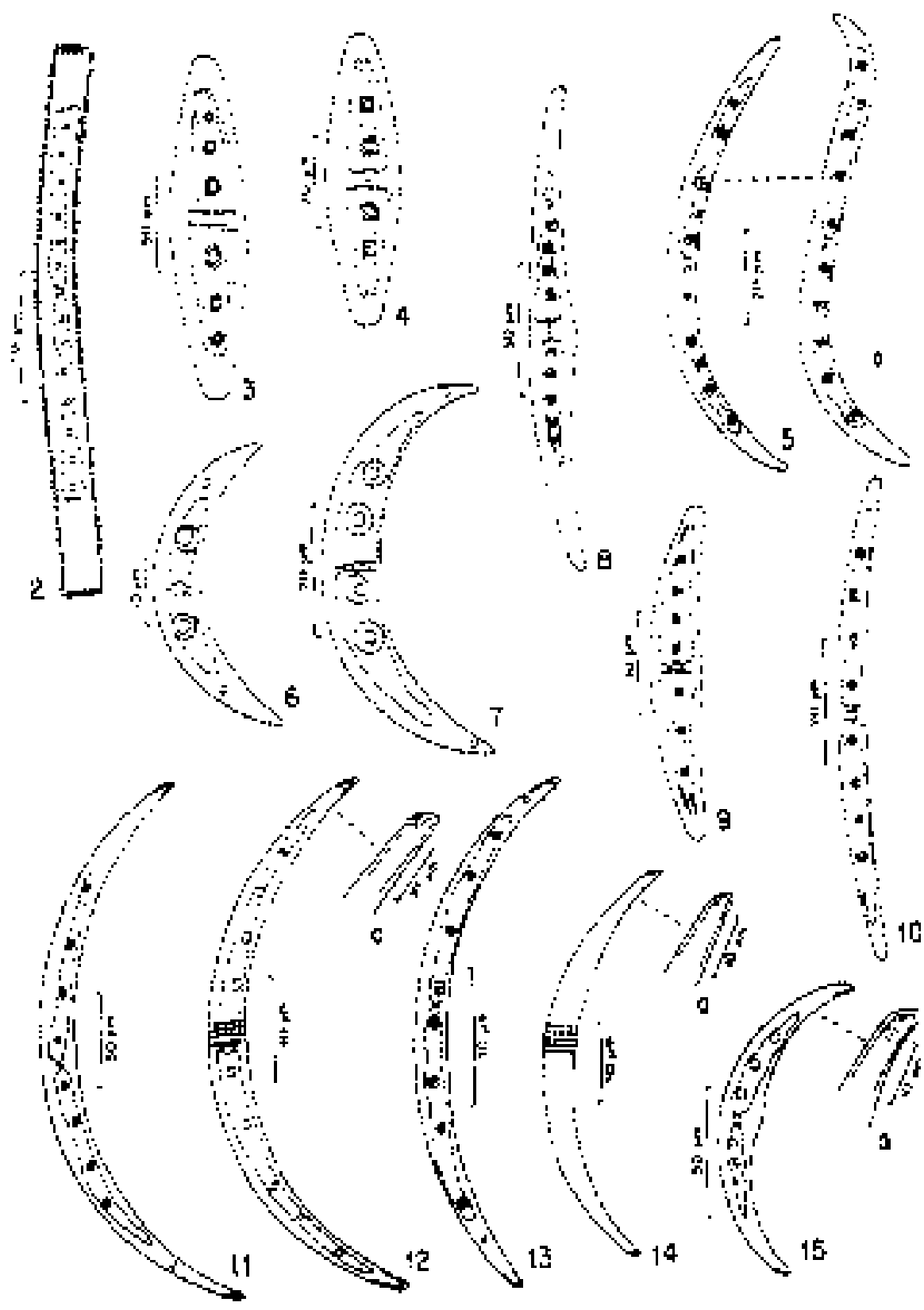

$\therefore$

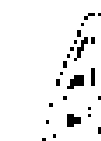

$\therefore$

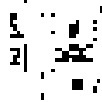

-

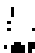

$\therefore$

; 1

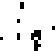

니:

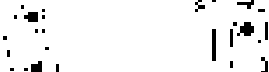

i

9

1

1)

i.

: 10
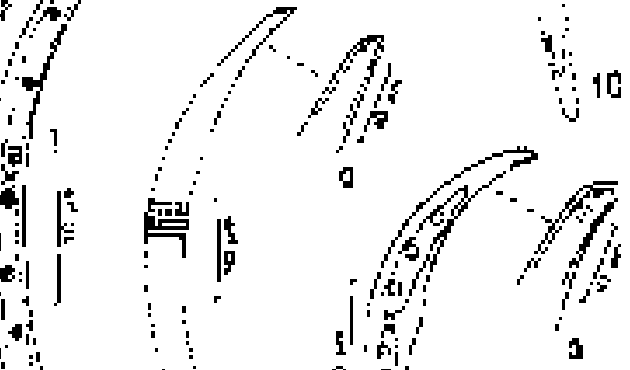

Figura 2 - Gonatozygon pilosum var. pilosum. Fig. 3. Closterium closterioides var. closterioides. Fig. 4. C. navicula var. navicula. Fig. 5. C. tortum; a: expressão morfológica sigmóide. Fig. 6-7. C. incurvum var. incurvum. Fig. 8-9. C. tumidum var. tumidum. Fig. 10. C. acutum var. acutum. Fig. 11-12. C. dianae var. arcuatum; a: ápice celular. Fig. 13-14. C. dianae var. minus; a: ápice celular. Fig. 15. C. dianae var. brevius; a: ápice celular. 
7,5 vezes mais comprida que larga, $(90-135 \mathrm{x}$ 15-19 $\mu \mathrm{m})$, cloroplastídio axial, pirenóides 3-5 em série mediana.

Distribuição geográfica no estado do Amazonas: rio Juruena (Uherkovich 1981).

Material examinado: SP239181, SP239189.

Closterium moniliferum (Bory) Ehrenberg ex Ralfs var. moniliferum f. moniliferum Brit. Desm. 166, pl. 28, fig. 3. 1848. (Fig. 16-17).

Célula curvada (140-160 de arco), 5,46,5 vezes mais comprida que larga (225-255 x $39-45 \mu \mathrm{m})$, cloroplastídio axial, cristas 3-4, pirenóides 7-9 em série mediana.

Distribuição geográfica no estado do Amazonas: lago Novo Andirá (primeira citação da ocorrência da espécie).

Material examinado: SP239192, SP239194, SP239195, SP239197, SP239199, SP239200, SP239201, SP239202, SP239210, SP239221, SP239222.

Closterium moniliferum (Bory) Ehrenberg ex Ralfs var. nasutum Rich Trans. R. Soc. S. Afr., 20(2): 166, fig. 5B-C. 1932. (Fig. 18).

Célula curvada ( $130-145^{\circ}$ de arco), 5,26,8 vezes mais comprida que larga (180-270 x 30-40 $\mu \mathrm{m}$ ), cloroplastídio axial, pirenóides 4-7 em série mediana.

Distribuição geográfica no estado do Amazonas: lago Novo Andirá (primeira citação da ocorrência da espécie).

Material examinado: SP239181, SP239198, SP239200, SP239215, SP239219, SP239221.

Closterium ehrenbergii Meneghini ex Ralfs var. ehrenbergii Brit. Desm. 166, pl. 28, fig. 2. 1848. (Fig. 19).

Célula lunada, fortemente curvada (130$160^{\circ}$ de arco), 5-6,2 vezes mais comprida que larga (198-270 x 35-45 $\mu \mathrm{m})$, cloroplastídio axial, cristas 3-4, pirenóides numerosos, espalhados.

Distribuição geográfica no estado do Amazonas: rio Negro (Uherkovich 1976).

Material examinado: SP239181, SP239183, SP239184, SP239185, SP239187, SP239192, SP239200, SP239219, SP239220.

Closterium turgidum Ehrenberg ex Ralfs var. giganteum (Nordstedt) De Toni Syll. Algar., 1: 828. 1889. (Fig. 20).
Célula curvada (ca. $20^{\circ}$ de arco), retilínea no terço mediano, 7,8-8,9 vezes mais comprida que larga $(850-900 \times 95-115 \mu \mathrm{m})$, parede celular estriada (estrias 5-8 em $10 \mu \mathrm{m}$ ), cloroplastídio axial, cristas ca. 6 , pirenóides muitos, espalhados.

Distribuição geográfica no estado do Amazonas: lago Novo Andirá (primeira citação da ocorrência da espécie).

Material examinado: SP239181.

Comentários: A população apresentou pequena variação na forma dos ápices celulares, com achatamento de um ou de ambos os lados.

Closterium lunula (Müller) Nitzsch ex Ralfs var. biconvexum Schmidle Österr. bot. Z., 45(8): 309, pl. 14, fig. 18. 1895. (Fig. 21).

Célula curvada (ca. $40^{\circ}$ de arco), 5-5,8 vezes mais comprida que larga (520-600 x 98$115 \mu \mathrm{m})$, cloroplastídio axial, cristas 4-6, pirenóides muitos, espalhados; vacúolo terminal; corpúsculo trepidante 1 .

Distribuição geográfica no estado do Amazonas: lago Novo Andirá (primeira citação da ocorrência da variedade).

Material examinado: SP239185 e SP239214.

Closterium baillyanum (Brébisson) Brébisson var. baillyanum Mém. Soc. Imp. Sci. nat. Cherbourg, 4: 151. 1856. (Fig. 22).

Célula curvada $\left(40-50^{\circ}\right.$ de arco), 10,811,9 vezes mais comprida que larga (298-310 x 25-28 $\mu \mathrm{m}$ ), cloroplastídio axial, pirenóides 56 em série mediana.

Distribuição geográfica no estado do Amazonas: igarapé Acará (Uherkovich \& Franken 1980).

Material examinado: SP239181, SP239195, SP239217.

Closterium nematodes Joshua var. nematodes J. Linn. Soc. Lond., 21: 652, pl. 22, fig. 7-9. 1886. (Fig. 23).

Célula curvada $\left(130-160^{\circ}\right.$ de arco), 8,810,6 vezes mais comprida que larga (150-186 x $15-18 \mu \mathrm{m}$ ), parede celular estriada (estrias ca. $8 \mathrm{em} 10 \mu \mathrm{m})$, cloroplastídio axial, pirenóides 57 em série mediana; vacúolo terminal, corpúsculo trepidante 1 .

Distribuição geográfica no estado do Amazonas: rio Maués-assu (Förster (1974):.

Material examinado: SP239181.

Comentários: A espécie é única pela 


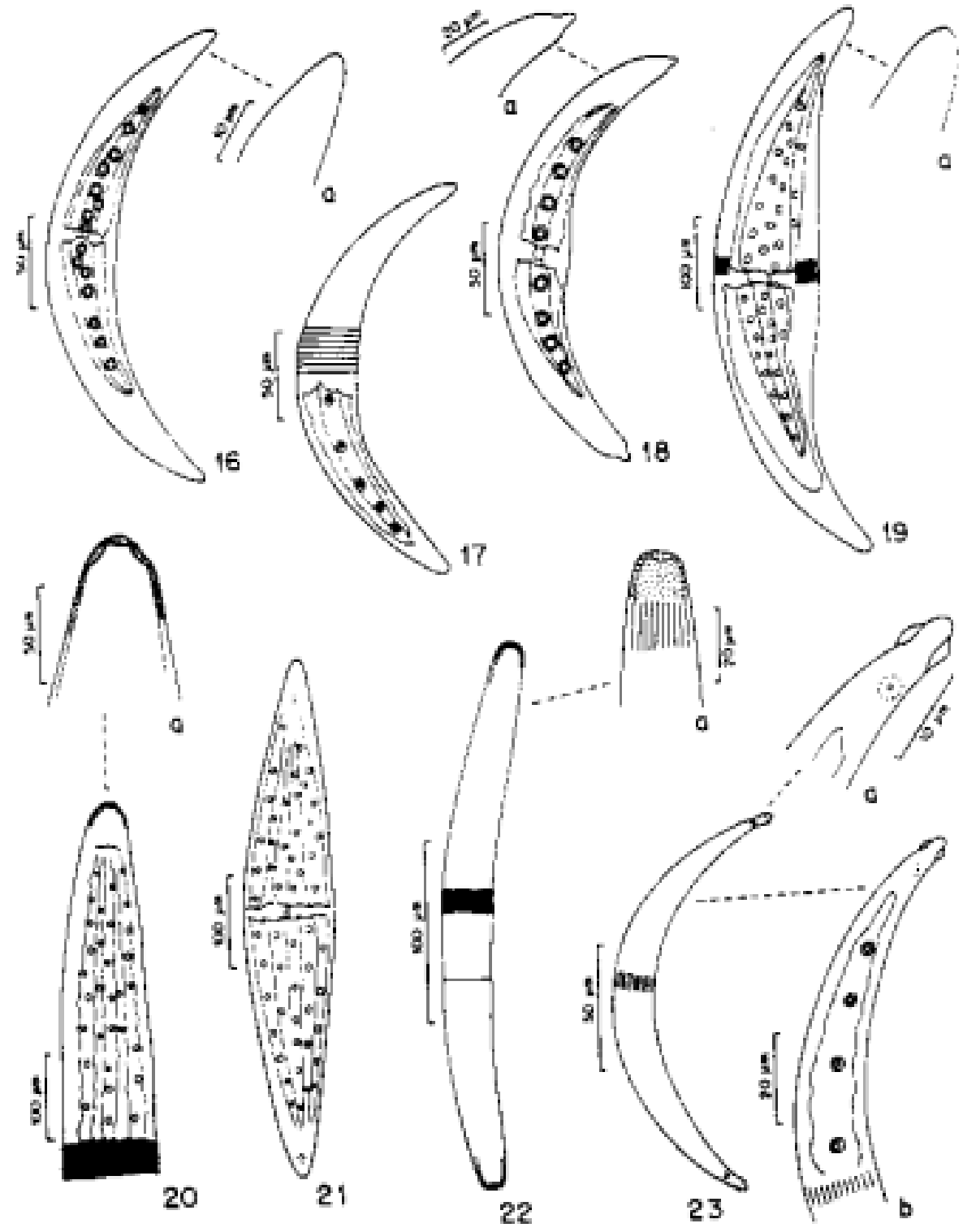

Figura 16-17 - Closterium moniliferum var. moniliferum; a: ápice celular. Fig. 18. C. moniliferum var. nasutum; a: ápice celular. Fig. 19. C. ehrenbergii var. ehrenbergii; a: ápice celular. Fig. 20. C. turgidum var. giganteum; a: ápice celular. Fig. 21. C. lunula var. biconvexum. Fig. 22. C. baillyanum var. baillyanum; a: ápice celular. Fig. 23. C. nematodes var. nematodes; a: ápice celular; b: semicélula. 
presença de um espessamento subapical da parede celular, com a forma de anel.

Closterium kuetzingii Brébisson var. kuetzingii Mém. Soc. Imp. Sci. nat. Cherbourg, 4: 156, pl. 2, fig. 40. 1856. (Fig. 24).

Célula reta, 20,7-33,2 vezes mais comprida que larga $(420-500 \times 15-23 \mu \mathrm{m})$, processos apicais setáceos (ca. 1/3 do compr. total da célula), parede celular estriada (estrias 14-19 em 10 $\mu \mathrm{m}$ ), cloroplastídio axial, pirenóides 5-7 em série mediana.

Distribuição geográfica no estado do Amazonas: rio Madeira (Förster 1974), lago Cristalino (Martins 1982), Lago do Castanho (Uherkovich \& Schmidt 1974), rio Negro (Uherkovich 1976), rio Jauaperi (Uherkovich \& Rai 1979), rios Abacaxis, Canumã, Juruena, Madeira, Maués-assu, Maués-mirim, Paraconí, lagos Cristalino, Calado, do Piranha e Paraná do Piranha (Uherkovich (1981).

Material examinado: SP239181, SP239182, SP239184.

Closterium rostratum Ehrenberg ex Ralfs var.rostratum Brit. Desm. 175, pl. 30, fig. 3. 1848. (Fig. 25).

Célula curvada, (ca. $20^{\circ}$ de arco), 17,219,3 vezes mais comprida que larga (350-470 x 19,5-26 $\mu \mathrm{m})$, processos apicais setáceos (1/5 do compr. total da célula), parede celular estriada (estrias 8-10 em $10 \mu \mathrm{m}$ ), cloroplastídio axial, pirenóides 6-7 em série mediana.

Distribuição geográfica no estado do Amazonas: reservatório de Balbina (Bittencourt-Oliveira 1993c).

Material examinado: SP239181, SP239182, SP239184.

Closterium lineatum Ehrenberg ex Ralfs var. lineatum Brit. Desm. 173, pl. 30, fig. 1. 1848. (Fig. 26).

Célula curvada (ca. $20^{\circ}$ de arco), 21,622,8 vezes mais comprida que larga (570-650 x 25-29 $\mu \mathrm{m}$ ), parede celular estriada (estrias 68 em $10 \mu \mathrm{m})$, espessamento apical; cloroplastídio axial, pirenóides 9-11 em série mediana.

Distribuição geográfica no estado do Amazonas: rio Maués-assu (Förster 1974), lago Cristalino, lago São Sebastião (Martins 1982).

Material examinado: SP239181, SP239200, SP239221.

\section{Família DESMIDIACEAE}

Pleurotaenium Nägeli

Chave artificial para identificação das espécies de Pleurotaenium

1. Semicélula subovada P. maskellii

1. Semicélula cilíndrica .P. ehrenbergii var. ehrenbergii

Pleurotaenium ehrenbergii (Brébisson) De Bary var. ehrenbergii Conjugaten. 75. 1858. (Fig. 27).

Célula 17,2-22,2 vezes mais comprida que larga (660-840 x 35-50,7 $\mu \mathrm{m}$; istmo 25 $35 \mu \mathrm{m}$ larg., ápice celular $25-42 \mu \mathrm{m}$ larg.), semicélula subcilíndrica, cloroplastídios vários, parietais, fitáceos, pirenóides numerosos, esparsos.

Distribuição geográfica no estado do Amazonas: igarapé Acará Uherkovich \& Franken (1980).

Material examinado: SP239181, SP239186, SP239187, SP239189, SP239190, SP239194, SP239201, SP239202, SP239204, SP239205, SP239207, SP239211, SP239214, SP239215, SP239216, SP239217, SP239218, SP239219, SP239222.

Pleurotaenium maskellii Suxena \& Venkateswarlu Phykos, 5(1-2): 256, fig. 1-2. 1966. (Fig. 28).

Célula 2,8-3 vezes mais comprida que larga $(225-450 \times 80-150 \mu \mathrm{m}$, istmo $45-80 \mu \mathrm{m}$ larg., ápice celular ca. $39 \mu \mathrm{m}$ larg.), semicélula subovóide, cloroplastídios parietais, em placas irregulares, pirenóides 1-2 por placa.

Distribuição geográfica no estado do Amazonas: lago Novo Andirá (primeira citação da ocorrência da espécie).

Material examinado: SP239181.

Euastrum Ehrenberg

Chave artificial para identificação das espécies, variedades e formas taxonômicas de Euastrum mediana.

1. Lobo apical com incisão apical

2. Lobos basais divididos em lóbulos.

3. Lobo apical com espinhos submarginais; lóbulos basais superiores com 3 espinhos marginais ....................... E. abruptum var. abruptum f. abruptum 
3. Lobo apical sem espinhos submarginais; lóbulos basais superiores com 2 espinhos marginais E. abruptum var. verrucosum

2. Lobos basais inteiros, não divididos em lóbulos.

4. Semicélula piramidal-truncada.

5. Célula maior que 100 um compr.; parede celular grosseiramente pontuada E. didelta var. quadriceps

5. Célula menor que 100 um compr.; parede celular finamente

pontuada E. ansatum var. ansatum f. ansatum

4. Semicélula de outras formas.

6. Semicélula transversalmente retangular E. rectangulare

6. Semicélula trapeziforme ou subtrapeziforme.

7. Semicélula subtrapeziforme E. fissum var. brasiliense

7. Semicélula trapeziforme.

8. Célula maior que $40 \mu \mathrm{m}$ compr.; lobo apical projetado

para cima E. quebecense

8. Célula até $40 \mu \mathrm{m}$ compr.; lobo apical não projetado

para cima E. elegans var. elegans f. elegans mediana.

1. Lobo apical sem incisão apical

9. Margem apical suavemente biconvexa E. subintegrum var. brasiliense

9. Margem apical não biconvexa.

10. Lobos basais inteiros E. validum var. glabrum f. inflatum

10. Lobos basais divididos em lóbulos.

11. Lóbulos superiores menores que os inferiores; parede celular

densamente granulosa E. verrucosum var.

11. Lóbulos superiores e inferiores de tamanhos iguais; parede celular esparsamente granulosa E. gemmatum var. gemmatum f. latior

Euastrum ansatum Ehrenberg ex Ralfs var. ansatum f. ansatum Brit. Desm. 85, pl. 14, fig. 2a-f. 1848. (Fig. 29).
Célula 1,8-2 vezes mais comprida que larga (69-72 x 35-38 $\mu \mathrm{m}$; istmo 11-13 $\mu \mathrm{m}$ larg.; lobo apical $15-18 \mu \mathrm{m}$ larg.); semicélula piramidal-truncada, 3-lobada, parede celular finamente pontuada, lobo apical subquadrado, incisão apical moderadamente profunda, fechada, levemente espessada; vista lateral da semicélula piramidal, 5 intumescências basais.

Distribuição geográfica no estado do Amazonas: lago Novo Andirá (primeira citação da ocorrência da forma típica).

Material examinado: SP239181, SP239184, SP239222.

Euastrum didelta (Turpin) Ralfs var. quadriceps (Nordstedt) Krieger In Rabenhorst, Kryptogamen-Fl. Deutschl., 13(1): 520, pl. 67, fig. 8-10. 1937. (Fig. 30).

Célula 1,9-2,1 vezes mais comprida que larga (125-135 x 60-68 $\mu \mathrm{m}$; istmo $15-20 \mu \mathrm{m}$ larg.; lobo apical 25-26 $\mu \mathrm{m}$ larg.); semicélula piramidal-truncada, 3-lobada, parede celular grosseiramente pontuada, lobo apical subquadrado, incisão apical moderadamente profunda, lobos basais inteiros; vista lateral da semicélula piramidal-truncada.

Distribuição geográfica no estado do Amazonas: região de Nhamundá e Terra Santa. (Thomasson 1977).

Material examinado: SP239181, SP239182, SP239222.

Euastrum rectangulare Fritsh \& Rich Trans. Roy. Soc. S. Afr., 25(2): 174, fig. 5MN. 1937. (Fig. 31).

Célula 1,2-1,5 vezes mais comprida que larga (13-19 x 9-14 $\mu \mathrm{m}$; istmo 3-4 $\mu \mathrm{m}$ larg.; lobo apical $9-13 \mu \mathrm{m} \quad$ larg.); semicélula transversalmente retangular, 3-lobada, parede celular lisa, lobo apical retangular, incisão apical mediana pouco profunda, aberta, em forma de V, lobos basais inteiros, tão largos quanto o lobo apical; vista lateral da semicélula oval; vista apical da célula elíptica, 1 espinho apical, margens laterais com 1 mamilo mediano.

Distribuição geográfica no estado do Amazonas: lago Novo Andirá (primeira citação da ocorrência da espécie).

Material examinado: SP239181, SP239197, SP239211, SP239219, SP239222.

Euastrum elegans (Brébisson) Kützing ex Ralfs var. elegans Brit. Desm. 89, pl. 14, fig. 7a-c. 1848. (Fig. 32). 
Célula 1,3-1,5 vezes mais comprida que larga (29-40 x 19-30 $\mu \mathrm{m}$; istmo $8 \mu \mathrm{m}$ larg.; lobo apical $10-19 \mu \mathrm{m}$ larg.); semicélula trapeziforme, 3-lobada, parede celular lisa, lobo apical subretangular, incisão apical mediana moderadamente profunda, 2 grânulos subapicais, lobos basais inteiros; vista lateral da semicélula oval, 1 espinho subapical; vista apical da célula elíptica, 1 espinho em cada ápice.

Distribuição geográfica no estado do Amazonas: lago Novo Andirá (primeira citação da ocorrência da espécie).

Material examinado: SP239181, SP239198 e SP239218.

Euastrum validum West \& West var. glabrum Krieger f. inflatum Prescott In Prescott et al., Syn. N.A. Desmids, 2(2): 70, fig. 3-3b. 1977. (Fig. 33-34).

Célula 1,2-1,4 vezes mais comprida que

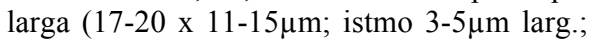
lobo apical $8-9 \mu \mathrm{m}$ larg.); semicélula trapeziforme, 3-lobada, face da semicélula com 1 poro de mucilagem central, parede celular lisa; lobo apical truncado, inteiro, lobos basais inteiros; vista lateral da semicélula oval; vista apical da célula elíptica, espessamento lateral em ambas vistas, mostrando poro de mucilagem conspícuo, submarginal, de cada lado da semicélula.

Distribuição geográfica no estado do Amazonas: lago Novo Andirá (primeira citação da ocorrência da variedade).

Material examinado: SP239181, SP239211.

Euastrum fissum West \& West var. brasiliense Krieger In Rabenhorst, Kryptogamen-Fl. Deutschl., 13(1): 596, pl. 82, fig. 16-18. 1937. (Fig. 35).

Célula 1,6-1,8 vezes mais comprida que larga (42-48 x 25-29 $\mu \mathrm{m}$; istmo ca. $7 \mu \mathrm{m}$ larg.); semicélula subtrapeziforme, 3-lobada, parede celular lisa, lobo apical truncado, projetado lateralmente em processos curtos, 1 processo de cada lado, no terço superior da semicélula, incisão apical mediana profunda, lobos basais inteiros.

Distribuição geográfica no estado do Amazonas: lago Novo Andirá (primeira citação da ocorrência da espécie).

Material examinado: SP239181, SP239184, SP239198.
Euastrum abruptum Nordstedt var. verrucosum Krieger In Rabenhorst, Kryptogamen-Fl., 13(1): 606, pl. 83, fig. 9-10. 1937. (Fig. 36).

Célula 1,1-1,2 vezes mais comprida que larga (40-44 x 37 $\mu \mathrm{m}$; istmo 6-8 $\mu \mathrm{m}$ larg.; lobo apical $22-27 \mu \mathrm{m}$ larg.).

Distribuição geográfica no estado do Amazonas: lago Novo Andirá (primeira citação da ocorrência da variedade).

Material examinado: SP239181, SP239187, SP239218.

Comentárioss: Esta variedade difere da variedade-tipo da espécie pela ausência de espinhos submarginais no lobo apical, sendo esta região decorada com 4 verrugas, 2 de cada lado da incisão apical mediana.

Euastrum abruptum Nordstedt var. abruptum f. abruptum Vidensk. Meddr dansk naturh. Foren., 1869(14-15): 217. 1869 (1870); 1887: pl. 2, fig. 3. 1887. (Fig. 37).

Célula 1,2-1,3 vezes mais comprida que larga (44-60 x 33-45 $\mu \mathrm{m}$; istmo 9-10 $\mu \mathrm{m}$ larg.; lobo apical 29-30 $\mu \mathrm{m}$ larg.); semicélula subtrapeziforme, 3-lobada, espinhos e grânulos submarginais, parede celular lisa, face da semicélula com 1 protrusão mediana ornada com 3 grânulos, lobo apical sub-retangular, incisão apical mediana profunda, 2-3 espinhos submarginais; conjunto dos lobos basais 2lobulado.

Distribuição geográfica no estado do Amazonas: região de Nhamundá e Terra Santa (Thomasson 1977).

Material examinado: SP239181, SP239184, SP239218.

Euastrum quebecense Irénée-Marie Flore Desm. Montreal. 132, pl. 18, fig. 16-17.1939. (Fig. 38).

Célula 1,1-1,6 vezes mais comprida que larga (45-51 x 30-42 $\mu \mathrm{m}$; istmo 5-9 $4 \mathrm{~m}$ larg.; lobo apical $22-25 \mu \mathrm{m}$ larg.); semicélula trapeziforme, 3-lobada, parede celular lisa, lobo apical sub-retangular, incisão apical mediana profunda, aberta, lobos basais inteiros; vista lateral da semicélula oval; vista apical da célula elíptica.

Distribuição geográfica no estado do Amazonas: lago Novo Andirá (primeira citação da ocorrência da espécie). 

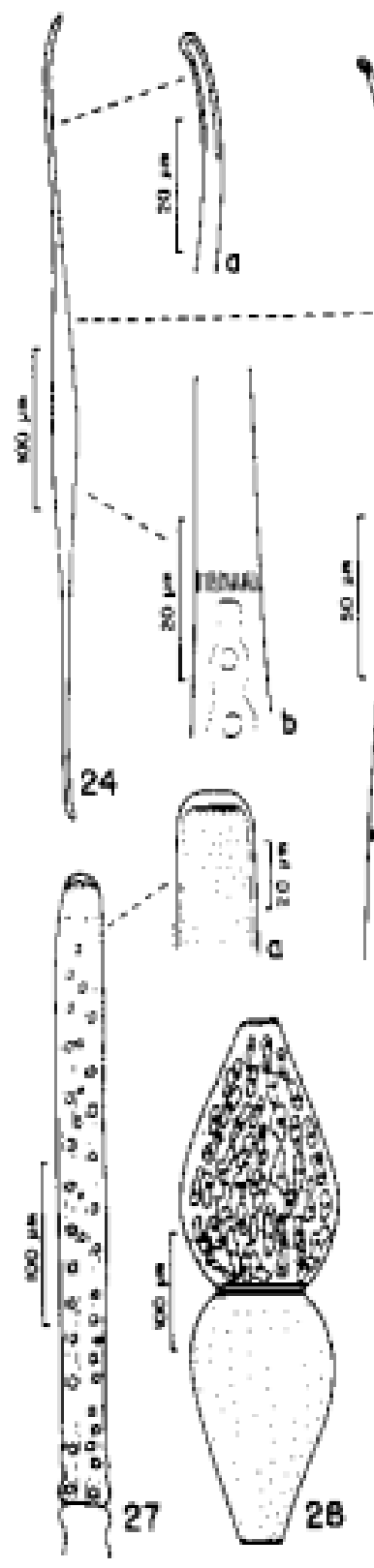
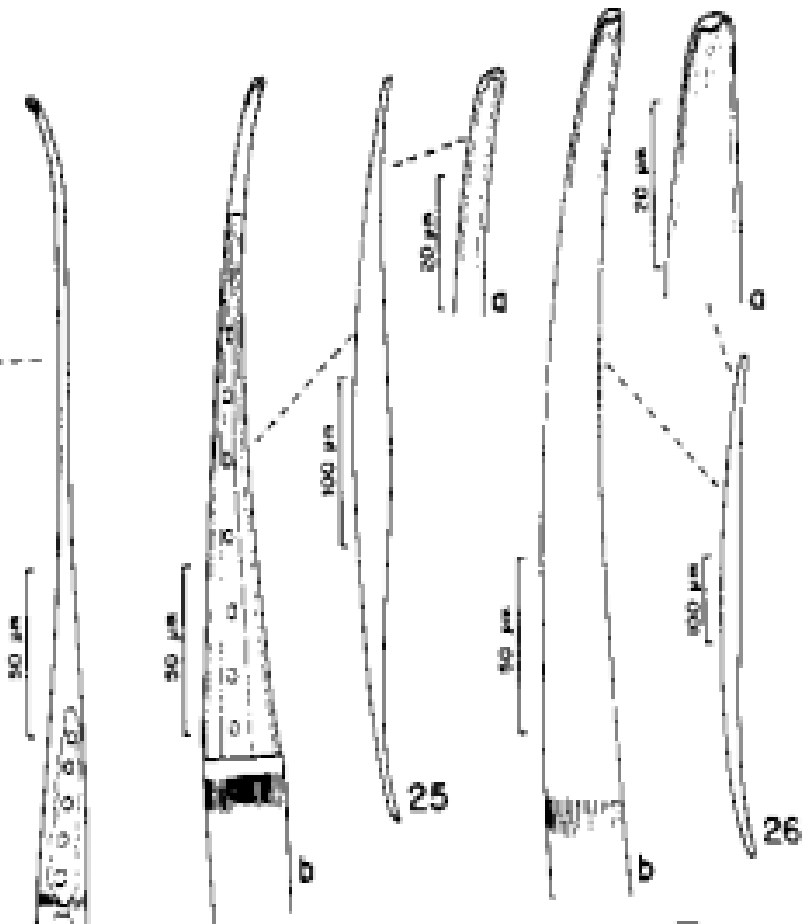

25
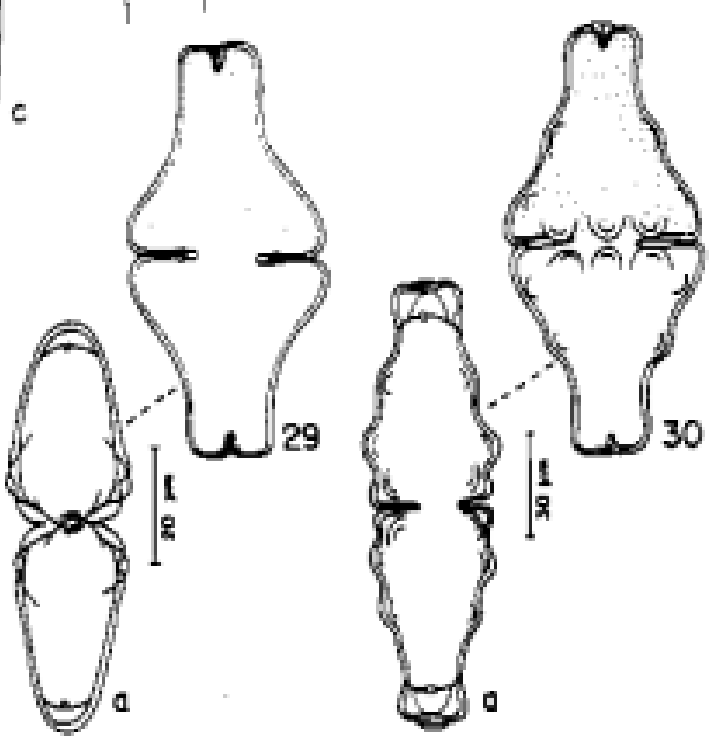

Figura 24 - Closterium kuetzingii var. kuetzingii; a: ápice celular; b: estrias; c: semicélula. Fig. 25. C. rostratum var. rostratum; a: ápice celular; b: semicélula. Fig. 26. C. lineatum var. lineatum; a: ápice celular; b: semicélula. Fig. 27. Pleurotaenium ehrenbergii var. ehrenbergii; a: ápice celular. Fig. 28. P. maskellii. Fig. 29. Euastrum ansatum var. ansatum f. ansatum; a: vista lateral. Fig. 30. E. didelta var. quadriceps; a: vista lateral. 

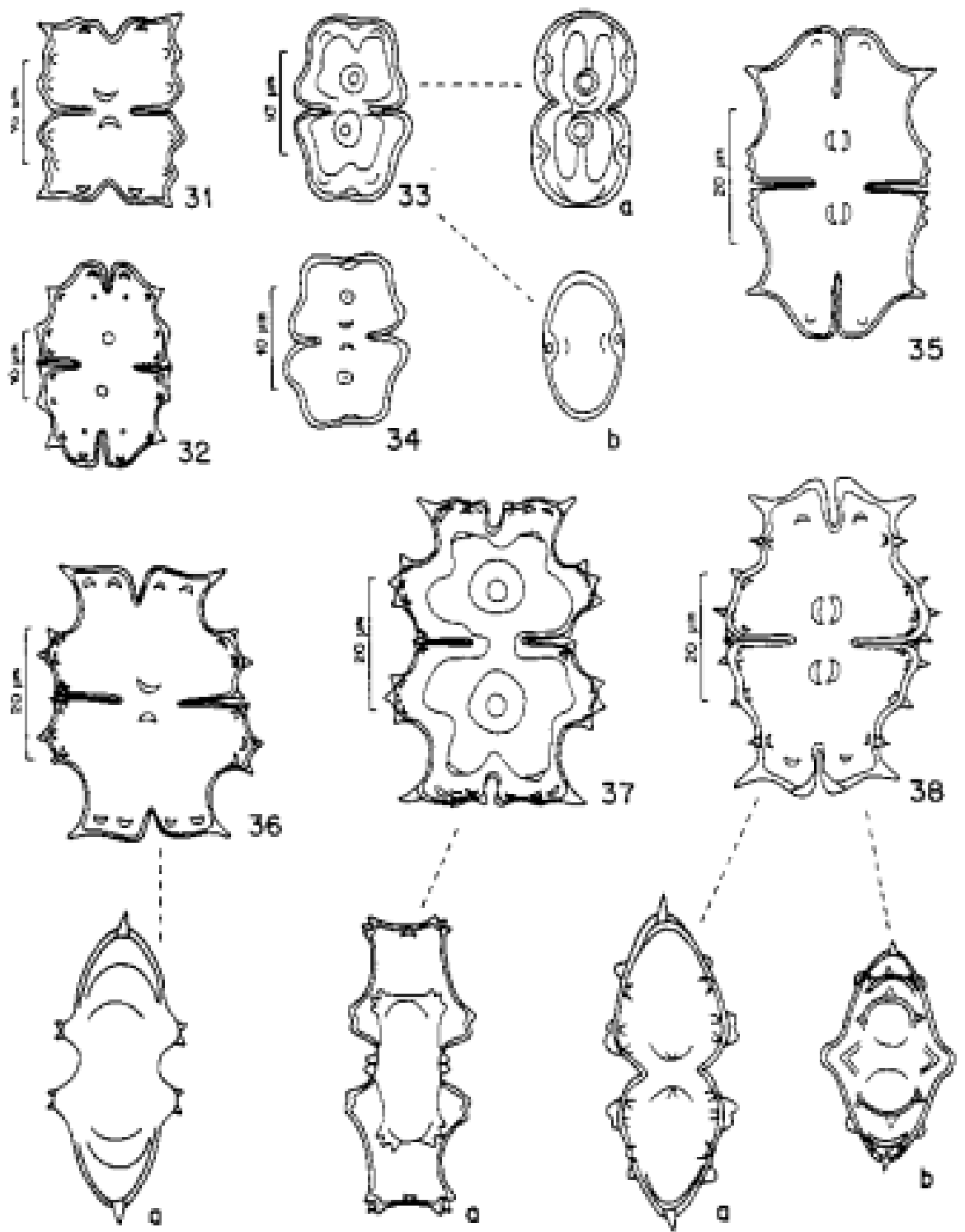

Figura 31 - Euastrum rectangulare. Fig. 32. E. elegans var. elegans. Fig. 33-34. E. validum var. glabrum f. inflatum; a: vista lateral; b: vista apical. Fig. 35. E. fissum var. brasiliense. Fig. 36. E. abruptum var. verrucosum; a: vista lateral. Fig. 37. E. abruptum var. abruptum f. abruptum; a: vista lateral. Fig. 38. E. quebecense; a: vista lateral; b: vista apical. 
Material examinado: SP239181, SP239182 e SP239218.

Euastrum subintegrum Nordstedt var. brasiliense Grönblad Acta Soc. Sci. fenn.: sér. B, 2(6): 14, fig. 69-70. 1945. (Fig. 39).

Célula 1,2-1,3 vezes mais comprida que larga (60-68 x 50-55 $\mu \mathrm{m}$; istmo $8-10$ $\mu \mathrm{m}$ larg.; lobo apical 28-30 $\mu \mathrm{m}$ larg.); semicélula subtrapeziforme, 3-lobada, face da semicélula com 4 escrobículos, cada 1 com 1 poro central, sendo 2 subapicais, parede celular finamente pontuada, lobo apical subcuneiforme, inteiro, lobos basais 2lobulados; vista lateral da semicélula oval, levemente constrita.

Distribuição geográfica no estado do Amazonas: igarapé Iaiana, rio Iá (Förster 1963).

Material examinado: SP239181, SP239182, SP239184.

Euastrum verrucosum Ehrenberg ex Ralfs Brit. Desm., p. 79, Pl. XI, Figs. 2a-2d var. (Fig. 40-42).

Célula 1-1,3 vezes mais comprida que larga (62-89 x 49-79 $\mu \mathrm{m}$; istmo 10-27 $\mu \mathrm{m}$ larg.; lobo apical $19-35 \mu \mathrm{m}$ larg.); semicélula piramidal-truncada, 3-lobada, face da semicélula com 1 protuberância basal, mediana, incisão entre os lobos basais profunda, aberta, em forma de U, parede celular pontuada, lobo apical cuneiforme, inteiro, lobos basais 2-lobulados; vista lateral da semicélula oval-truncada, inflada na base, protrusão basal granulosa, margens laterais convergindo para o ápice, crenuladas na base, lisas até o ápice, ápice truncado, retuso no meio, ângulos projetados para cima, crenulados; vista apical da célula subfusiforme, protrusão mediana granulosa, margens crenuladas, lisas apenas entre a protrusão e os ápices, ápices densamente granulados.

Material examinado: SP239181 e SP239217.

Comentários: Os exemplares examinados diferem daqueles da variedade-típica da espécie pela presença de características marcantes, tais como: (1) maior profundidade das incisões interlobares, que vão dar origem a lobos e lóbulos relativamente maiores e (2) apenas uma protrusão mediana, bem evidente na vista apical da célula, enquanto que a variedade-típica apresenta três. Tais características não estão registradas em literatura para qualquer variedade dentro da espécie, o que nos impediu de fazer comparação e identificação infra-específica dos presentes espécimes.

De-Lamonica-Freire (1985) descreveu e ilustrou uma população de $E$. verrucosum com as mesmas características partilhadas pelos atuais exemplares, no entanto, também não providenciou sua identificação taxonômica em nível infra-específico.

$\mathrm{Na}$ população ora estudada, foram observados dois grupos de indivíduos morfologicamente distintos entre si e da variedade-típica da espécie. Tais diferenças levaram-nos a supor tratar-se ou de novas formas taxonômicas ou da existência de um acentuado grau de polimorfismo da variedadetípica. Mais coletas e maior número de indivíduos deverão ser analisados para que se possa definir a situação sistemática do presente material.

Euastrum gemmatum (Brébisson) Ralfs var. gemmatum f. latior Grönblad Acta Soc. Sci. fenn.: sér. B, 2(6): 13, fig. 57. 1945. (Fig. 4344).

Célula 1-1,2 vezes mais comprida que larga (50-57 x 45-52 $\mu \mathrm{m}$; istmo $12-15 \mu \mathrm{m}$ larg.; lobo apical 19-22 $\mu \mathrm{m}$ larg.); semicélula subtrapeziforme, 3-lobada, parede celular esparsamente granulosa, lobo apical subcuneiforme inteiro, lobos basais bilobulados, lóbulos ligeiramente voltados para cima; vista lateral da semicélula oval-truncada; vista apical da célula oblonga.

Distribuição geográfica no estado do Amazonas: região de Nhamundá e Terra Santa (Thomasson 1977).

Material examinado: SP239181, SP239184, SP239217.

Micrasterias C. Agardh

Chave artificial para identificação das espécies, variedades e formas taxonômicas de Micrasterias.

1. Semicélula 3-lobada.

2. Lobos basais 2-denticulados 
M. laticeps var. laticeps f. laticeps

2. Lobos basais acuminados M. laticeps var. acuminata

1. Semicélula 5-lobada.

3. Parede celular com grânulos ou espinhos.

4. Lobos laterais e basais divididos em lóbulos; parede celular irregularmente coberta por espinhos M. borgei var. multidentata

4. Lobos laterais e basais indiviso; parede celular com grânulos intramarginais ao longo das incisões $M$. mahabuleshwarensis var. amazonensis

3. Parede celular lisa ou finamente pontuada.

5. Célula menor que $100 \mu \mathrm{m}$ compr.

6. Lobo apical subcuneiforme, extremidades 2-denticuladas $M$. abrupta

6. Lobo apical subfusiforme, extremidades acuminadas M. truncata var.pusilla

5. Célula maior que $100 \mu \mathrm{m}$ compr.

7. Lobos laterais e basais divididos até 2 vezes.

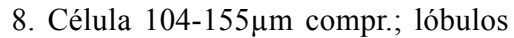
laterais até

$1^{\mathrm{a}}$ ordem M. furcata var. furcata

8. Célula 260-275 $\mu \mathrm{m}$ compr.; lóbulos laterais até

$2^{\mathrm{a}}$ ordem M. torreyi var. nordstedtiana

7. Lobulos laterais e basais divididos mais de 2 vezes.

9. Célula 158-220 $\mu \mathrm{m}$ compr.; lóbulos basais até

$3^{\mathrm{a}}$ ordem M. radiosa var. radiosa

9. Célula 235-270 $\mu \mathrm{m}$ compr.; lóbulos basais até

$2^{\mathrm{a}}$ ordem $M$.

rotata var. rotata

Micrasterias laticeps Nordstedt var. laticeps f. laticeps Vidensk. Meddr dansk naturh. Foren., 1869(14-15): 220. 18 69 (1870); 1887: pl. 2, fig. 14. $1887 . \quad$ (Fig. 45-50).
Célula $0,7-0,8$ vez mais comprida que larga (100-175 x 122-208 $\mu \mathrm{m}$; istmo 14$30 \mu \mathrm{m}$ larg.; lobo apical $70-208 \mu \mathrm{m}$ larg.); semicélula de contorno semicircular, 3lobada, incisões interlobares profundas, abertas, parede celular finamente pontuada, lobo apical transversalmente fusiforme, margem apical convexa, às vezes retusa no meio, ângulos acuminados, lobos basais semifusiformes, dispostos horizontalmente, 2-denticulados; vista lateral da semicélula elíptica; vista apical da célula fusiforme.

Distribuição geográfica no estado do Amazonas: rio Uaupés (Förster 1963), como Micrasterias laticeps Nordstedt var. crassa Prescott.

Material examinado: SP239181, SP239182, SP239184, SP239186, SP239187, SP239191, SP239194, SP239195, SP239196, SP239197, SP239199, SP239201, SP239202, SP239204, SP239205, SP239206, SP239207, SP239210, SP239211, SP239212, SP239213, SP239214, SP239215, SP239216, SP239217, SP239218, SP239219, SP239220, SP239221, SP239222.

Micrasterias laticeps Nordstedt var. acuminata Krieger In Rabenhorst, Kryptogamen-Fl. Deutschl., 13(2): 14, pl. 98, fig. 2. 1939. (Fig. 51-52).

Célula 0,7-0,8 vez mais comprida que

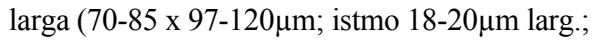
lobo apical $89-100 \mu \mathrm{m}$ larg).

Distribuição geográfica no estado do Amazonas: lago Novo Andirá (primeira citação da ocorrência da variedade).

Material examinado: SP239189, SP239191, SP239192, SP239193, SP239195, SP239196, SP239198, SP239202, SP239204, SP239207, SP239210, SP239211, SP239214, SP239215, SP239218, SP239220, SP239221.

Comentários: Esta variedade difere da variedade-típica da espécie por possuir as extremidades dos lobos basais acuminadas.

Micrasterias radiosa Ralfs var. radiosa Brit. Desm. 72, pl. 8, fig. 3. 1848. (Fig. 53). 
Célula $1-1,1$ vezes mais comprida que larga $(158-220 \times 156-210 \mu \mathrm{m}$; istmo 20-26 $\mu \mathrm{m}$ larg.; lobo apical 32-40 $\mu \mathrm{m}$ larg.); semicélula de contorno semicircular, 5-lobada, incisões interlobares profundas, semi-abertas, parede celular lisa, lobo apical subcilíndrico, ápice chanfrado, ângulos emarginados, 2-denticulados, lobos laterais e basais subdivididos até $3^{\text {a }}$ ordem, extremidades 2denticuladas.

Distribuição geográfica no estado do Amazonas: lago Novo Andirá (primeira citação da ocorrência da variedade-típica).

Material examinado: SP239191, SP239194, SP239201, SP239202, SP239210, SP239213, SP239214, SP239215, SP239217, SP239218, SP239213, SP239214, SP239215, SP239217, SP239218, SP239220.

Micrasterias mahabuleshwarensis Hobson var. amazonensis Förster Amazoniana, 2(1-2): 40, pl. 17, fig. 1-8. 1969. (Fig. 54).

Célula 1-1,2 vezes mais comprida que larga (100-150 x 100-125 $\mu \mathrm{m}$; istmo $22-30 \mu \mathrm{m}$ larg.; lobo apical 63-75 $\mu \mathrm{m}$ larg.); semicélula de contorno semielíptico, 5-lobada, incisões interlobares profundas, abertas, parede celular granulosa, lobo apical subcilíndrico, ápice retuso, ângulos projetados em processos divergentes, 3-denticulados, 1 par de processos acessórios, assimétricos, 3-denticulados, lobos laterais e basais cônico-truncados, inteiros, extremidades 3-denticuladas.

Distribuição geográfica no estado do Amazonas: lagos Cristalino, lago São Sebastião (Martins 1986b), paraná do Piranha (Uherkovich 1981).

Material examinado: SP239181, SP239182, SP239217, SP239219, SP239221.

Micrasterias torreyi Bailey ex Ralfs var. nordstedtiana (Hieronymus) Schmidle Bot. Jb., 26(1-2): 48. 1898. (Fig. 55).

Célula 1-1,1 vezes mais comprida que larga (260-275 x 240-245 $\mu \mathrm{m}$; istmo $40-41 \mu \mathrm{m}$ larg.; lobo apical 53-55 $\mu \mathrm{m}$ larg.); semicélula de contorno semicircular, 5-lobada, incisões interlobares profundas, semiabertas, parede celular finamente pontuada, lobo apical subcilíndrico, ápice retuso-chanfrado, ângulos projetados formando processos cônicos, 2denticulados, lobos laterais subdivididos até $2^{\mathrm{a}}$ ordem, lobos basais até $1^{\mathrm{a}}$ ordem, ambos com extremidades 2-denticuladas.

Distribuição geográfica no estado do Amazonas: lago Cristalino (Martins 1986b).

Material examinado: SP239202, SP239221.

Micrasterias borgei Krieger var. multidentata Krieger In Rabenhorst, Kryptogamen-Fl. Deutschl., 13(2): 86, fig. 5. 1939. (Fig. 56).

Célula ca. 1,1 vezes mais comprida que larga $(298-320 \times 250-275 \mu \mathrm{m}$; istmo 35-38 $\mu \mathrm{m}$ larg.; lobo apical 60-78 $\mu \mathrm{m}$ larg.); semicélula de contorno semicircular, 5-lobada, parede celular finamente pontuada, irregularmente coberta de espinhos, incisões interlobares profundas, semiabertas, lobo apical subcilíndrico, ápice retusochanfrado, ângulos projetados, 2-denticulados, lobos laterais subdivididos até $3^{\text {a }}$ ordem, lobos basais até $2^{a}$ ordem, ambos com extremidades 2-denticuladas.

Distribuição geográfica no estado do Amazonas: rio Cuieiras (Uherkovich \& Rai 1979), como uma forma anônima.

Material examinado: SP239181, SP239182, SP239219.

Micrasterias rotata (Greville) Ralfs ex Ralfs var. rotata Ann. Mag. nat. Hist., 14: 259, pl. 6, fig. 1. 1844. (Fig. 57).

Célula 1-1,1 vezes mais comprida que larga (235-270 × 205-256 $\mu \mathrm{m}$; istmo $30-40 \mu \mathrm{m}$ larg.; lobo apical $40-50 \mu \mathrm{m}$ larg.); semicélula de contorno semicircular, 5lobada, incisões interlobares profundas, semiabertas, parede celular finamente pontuada, lobo apical subcilíndrico, ápice, retusochanfrado, ângulos projetados formando processos cônicos, 2-denticulados, lobos laterais subdivididos até $3^{\mathrm{a}}$ ordem, lobos basais até $2^{\mathrm{a}}$ ordem, ambos com extremidades 2denticuladas.

Distribuição geográfica no estado do Amazonas: lago Cristalino, lago São Sebastião (Martins 1986b), rio Negro (Uherkovich 1976). 
Material examinado: SP239192, SP239198, SP239202, SP239204, SP239206, SP239207, SP239209, SP239210, SP239211, SP239212, SP239216, SP239217, SP239218, SP239220.

Micrasterias furcata C. Agardh ex Ralfs var. furcata Brit. Desm. 73, pl. 9, fig. 2. 1848. (Fig. 58).

Célula 1,1-1,2 vezes mais comprida que larga (128-182 x 104-155 $\mu \mathrm{m}$; istmo $16-20 \mu \mathrm{m}$ larg.; lobo apical 30-61 $\mu \mathrm{m}$ larg.); semicélula de contorno semicircular, 5-lobada, parede celular finamente pontuada, incisões interlobares profundas, abertas; lobo apical subcilíndrico, ápice retuso, ângulos projetados, 2denticulados, lobos laterais e basais 2-lobulados, extremidades 2-denticuladas.

Distribuição geográfica no estado do Amazonas: rio Maués-assu (Förster (1974), lago Rio Preto da Eva (Thomasson 1971), região de Nhamundá e Terra Santa (Thomasson 1977) como Micrasterias radiata Hassal var. groenbladii Croasdale, rio Negro (Uherkovich 1976), rio Maués-assu, paraná do Piranha Uherkovich (1981), como $M$. radiata var. brasiliensis Grönblad, lago Cristalino, lago São Sebastião (Martins 1986b).

Material examinado: SP239181, SP239182, SP239219.

Micrasterias abrupta West \& West Trans. Linn. Soc. Lond.: sér. 2, 5(5): 241, pl. 14, fig. 13-16. 1896. (Fig. 59).

Célula 0,8-0,9 vez mais comprida que larga (45-55 x 49-60 $\mu \mathrm{m}$; istmo 9-11 $\mu \mathrm{m}$ larg.; lobo apical 25-30 $\mu \mathrm{m}$ larg.); semicélula de contorno semicircular, 5-lobada, incisões interlobares profundas, abertas, parede celular finamente pontuada, lobo apical subcuneiforme, ângulos 2-denticulados, lobos lateris e basais 2-lobulados, extremidades 2denticuladas.

Distribuição geográfica no estado do Amazonas: lago Novo Andirá (primeira citação da ocorrência da espécie).

Material examinado: SP239181, SP239202, SP239219, SP239220.

Micrasterias truncata (Corda) Brébisson ex Ralfs var. pusilla G.S. West f. pusilla Mém. Soc. neuchât. Sci. nat., 5: 1035, pl. 22, fig. 42-42. 1914. (Fig. 60-61).

Célula 0,8-0,9 vez mais comprida que larga $(50-70$ x $54-80 \mu \mathrm{m}$; istmo $10-19 \mu \mathrm{m}$ larg.; lobo apical 38-59 $\mu \mathrm{m}$ larg.); semicélula de contorno semicircular, 5-lobada, incisões interlobares profundas, semiabertas, parede celular finamente pontuada, lobo apical subfusiforme, ápice truncado ou levemente convexo, ângulos acuminados, lobos laterais e basais 2-lobulados, extremidades 2denticuladas.

Distribuição geográfica no estado do Amazonas: lago São Sebastião (Martins 1986b), lago do Castanho (Uherkovich \& Schmidt 1974).

Material examinado: SP239181, SP239192, SP239194, SP239197, SP239198, SP239202, SP239204, SP239206, SP239207, SP239210, SP239214, SP239215, SP239216, SP239217, SP239218, SP239219, SP239220, SP239221, SP239222.

\section{Cosmarium Corda}

Chave artificial para identificação das espécies, variedades e formas taxonômicas de Cosmarium

1. Parede celular lisa ou finamente pontuada.

2. Margem celular apical crenulada ou ondulada.

3. Margem apical 5-crenulada var. glabrum C. humile

3. Margem apical 2-3-ondulada C. levinotabile var. heterocrenatum

2. Margem celular apical lisa. truncado.

4. Ápice celular truncado ou retuso-

5. Ápice celular retuso-truncado.

6. Célula maior que $50 \mu \mathrm{m}$ compr.

pyramidatum f. pyramidatum

6. Célula até $20 \mu \mathrm{m}$ compr.

7. Semicélula trapeziforme C. sublobatum var.

brasiliense 
7. Semicélula sub-retangular C. regnesii var.

montanum

5. Ápice celular truncado, não-retuso.

8. Margens celulares laterais 3-onduladas C. fontigenum var. pseudofontigenum

8. Margens celulares laterais lisas.

9. Margens laterais convergindo para o ápice; semicélula piramidal-truncada.

10. Célula $28-40 \mu \mathrm{m}$ compr. C. granatum var. granatum f. granatum

10. Célula 121-128 $\mu \mathrm{m}$ compr C. triangulare

9. Margens laterais não-convergindo para o ápice; semicélula de outras formas.

11. Semicélula hexagonal, formando ângulo no terço superior.

12. Ângulo projetado, vértice mais acentuadamente arredondado C. regnellii var. regnellii

12. Ângulo não projetado, vértice levemente arredondado C. rectangulare var. hexagonum

11. Semicélula de outra forma, não formando ângulo no terço superior.

13. Semicélula subtrapeziforme C. trilobulatum var. trilobulatum f. trilobulatum

13. Semicélula subquadrática .. $C$. exiguum var. exiguum f. exiguum

4. Ápice celular arredondado ou arredondado-truncado.

14. Ápice celular arredondado-truncado.

15. Semicélula semicircular .. $C$. candianum var. candianum f. candianum

15. Semicélula piramidal-truncada C. pyramidatum var. stephani

14. Ápice celular arredondado.

16. Semicélula subpiramidal C. pseudopyramidatum var. rotundatum

16. Semicélula subsemicircular.

17. Célula até $30 \mu \mathrm{m}$ compr.

18. Vista lateral da semicélula subcuneiforme, $4-18 \mu \mathrm{m}$ compr. C. clepsydra var. bicardia

18. Vista lateral da semicélula subcircular, $23-27 \mu \mathrm{m}$ compr. ...C. montrealense
17. Celula maior que $30 \mu \mathrm{m}$ compr.

19. Célula $75-132 \mu \mathrm{m}$ compr., constrição mediana profunda C. pachydermum var. pachydermum f. pachydermum

19. Célula 37-55 $\mu \mathrm{m}$ compr.; constrição mediana rasa ......... C. pseudoconnatum var. pseudoconnatum f. pseudoconnatum

1. Parede celular com grânulos ou espinhos.

20. Parede celular com espinhos C. denticulatum var. ovale

20. Parede celular com grânulos.

21. Célula maior que $50 \mu \mathrm{m}$ compr.

22. Margens laterais retas, levemente divergentes; ápice truncado . $C$. quadrum var. quadrum

22. Margens laterais convexas; ápice celular levemente arredondado.

23. Célula 72,9-77,6 $\mu \mathrm{m}$ compr. C. margaritatum var.

margaritatum f. margaritatum

23. Células 50,3-55,4 $\mu \mathrm{m}$ compr...........C. margaritatum var. margaritatum $\mathrm{f}$. minor

21. Célula menor do que $50 \mu \mathrm{m}$ compr.

24. Constrição mediana rasa; istmo escavado .............. C. excavatum var. excavatum

24. Constrição mediana profunda; istmo não escavado.

25. Seno mediano aberto em toda extensão C. comissurale var. crassum f. crassum

25. Seno mediano fechado em toda extensão.

26. Pirenóide 1 por semicélula.

27. Semicélula elíptico-oblonga, com grânulos faciais proeminentes C. dichondrum var. tumidum

27. Semicélula oblongo-trapeziforme, sem grânulos faciais ................... $C$. punctulatum var. punctulatum $\mathrm{f}$. punctulatum

26. Pirenóides 2 por semicélula.

28. Semicélula oblongo-trapeziforme, 20-32 $\mu \mathrm{m}$ compr. . Cosmarium sp. 1

28. Semicélula semicircular, $40-42 \mu \mathrm{m}$ compr. Cosmarium sp.2

Cosmarium candianum Delponte var. candianum f. candianum Mém. R. Accad. Sci. Torino, 28: 113, pl. 8, fig. 1-6. 1877. (Fig. 62). 

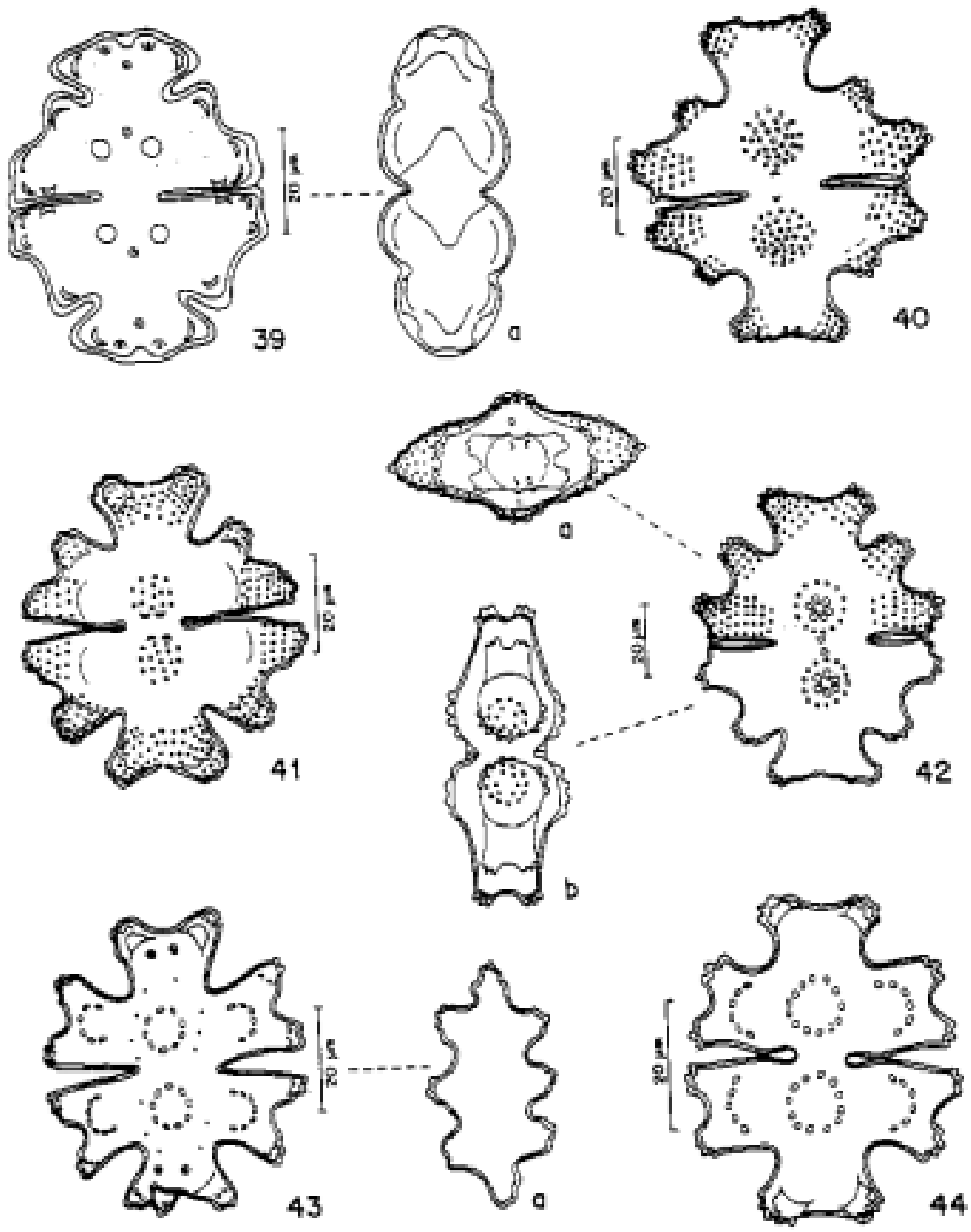

Figura 39. Euastrum subintegrum var. brasiliense; a: vista lateral. Fig. 40-42. E. verrucosum var.; a: vista apical; b: vista lateral. Fig. 43-44. E. gemmatum var. gemmatum f. latior; a: vista apical. 

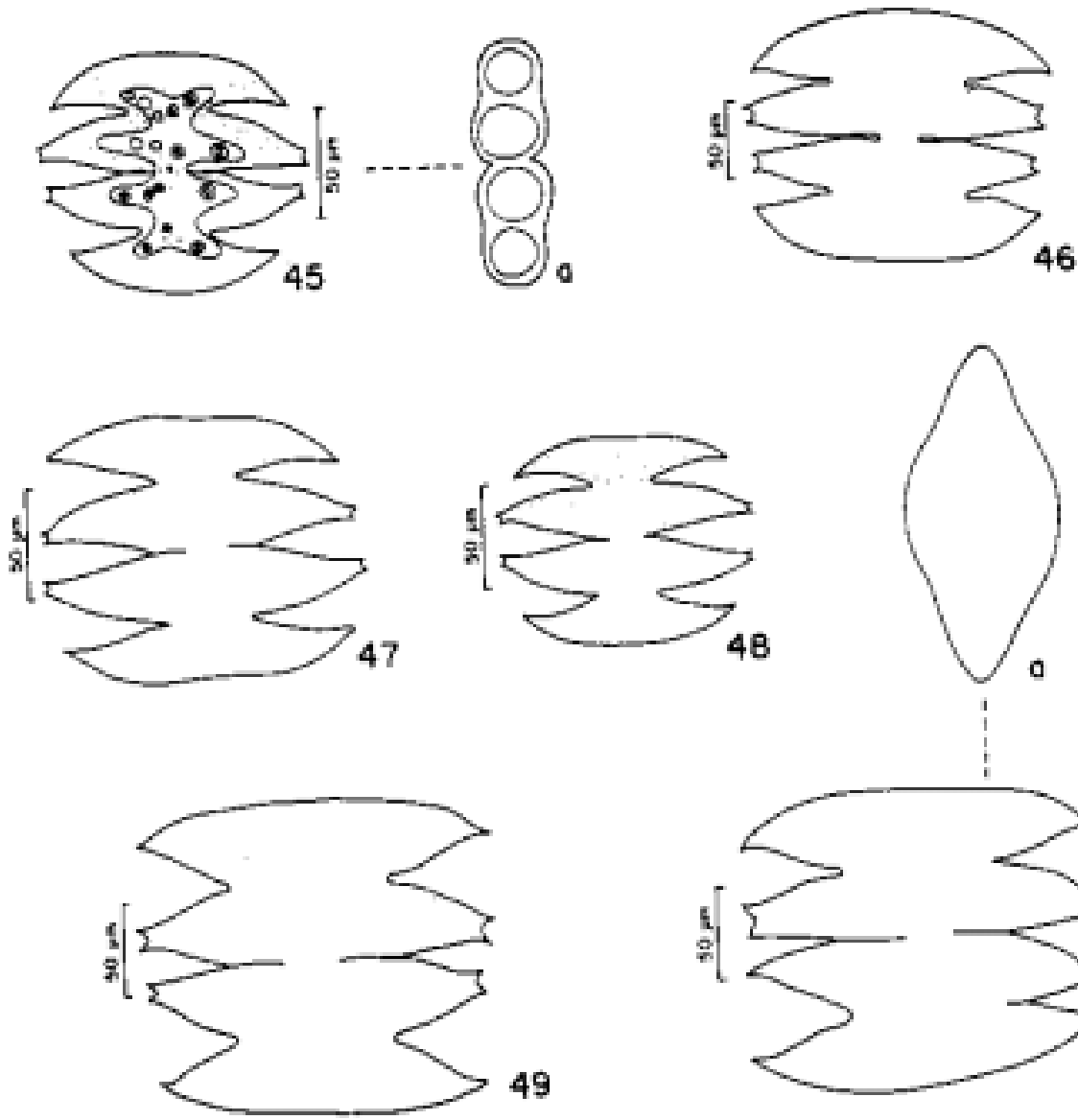

49
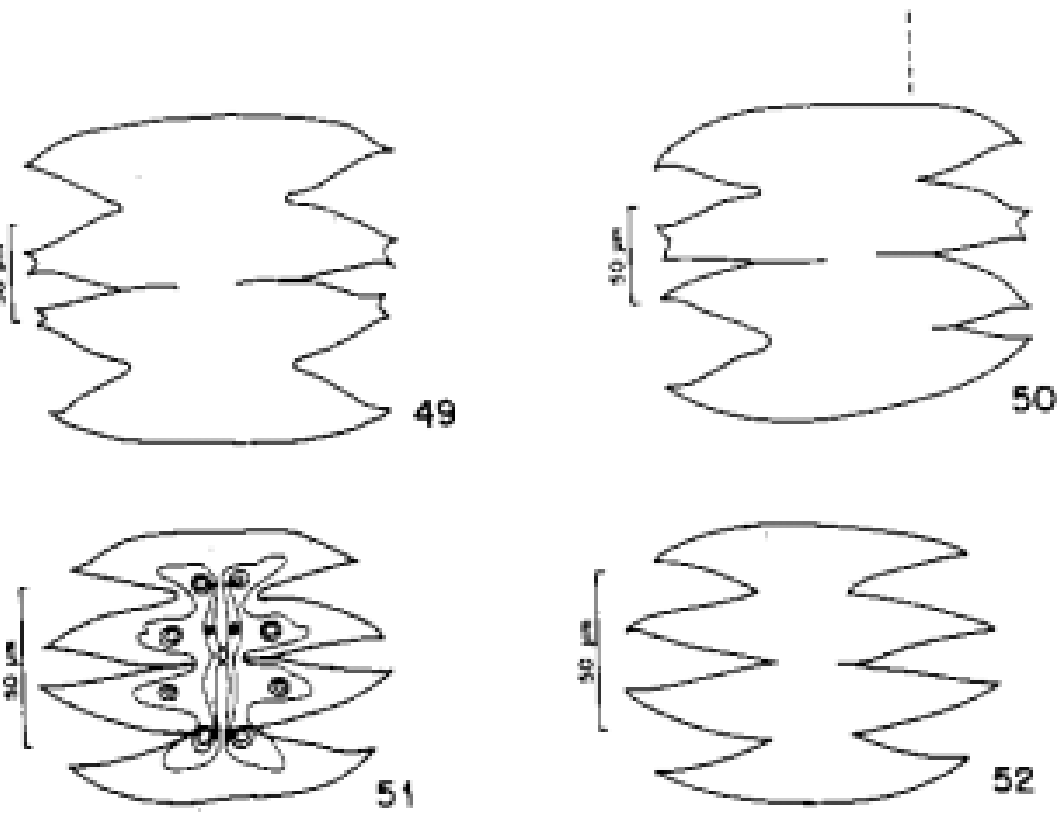

Figura 45-50. Micrasterias laticeps var. laticeps f. laticeps; a: vista lateral; b: vista apical. Fig. 51-52. M. laticeps var. acuminata. 

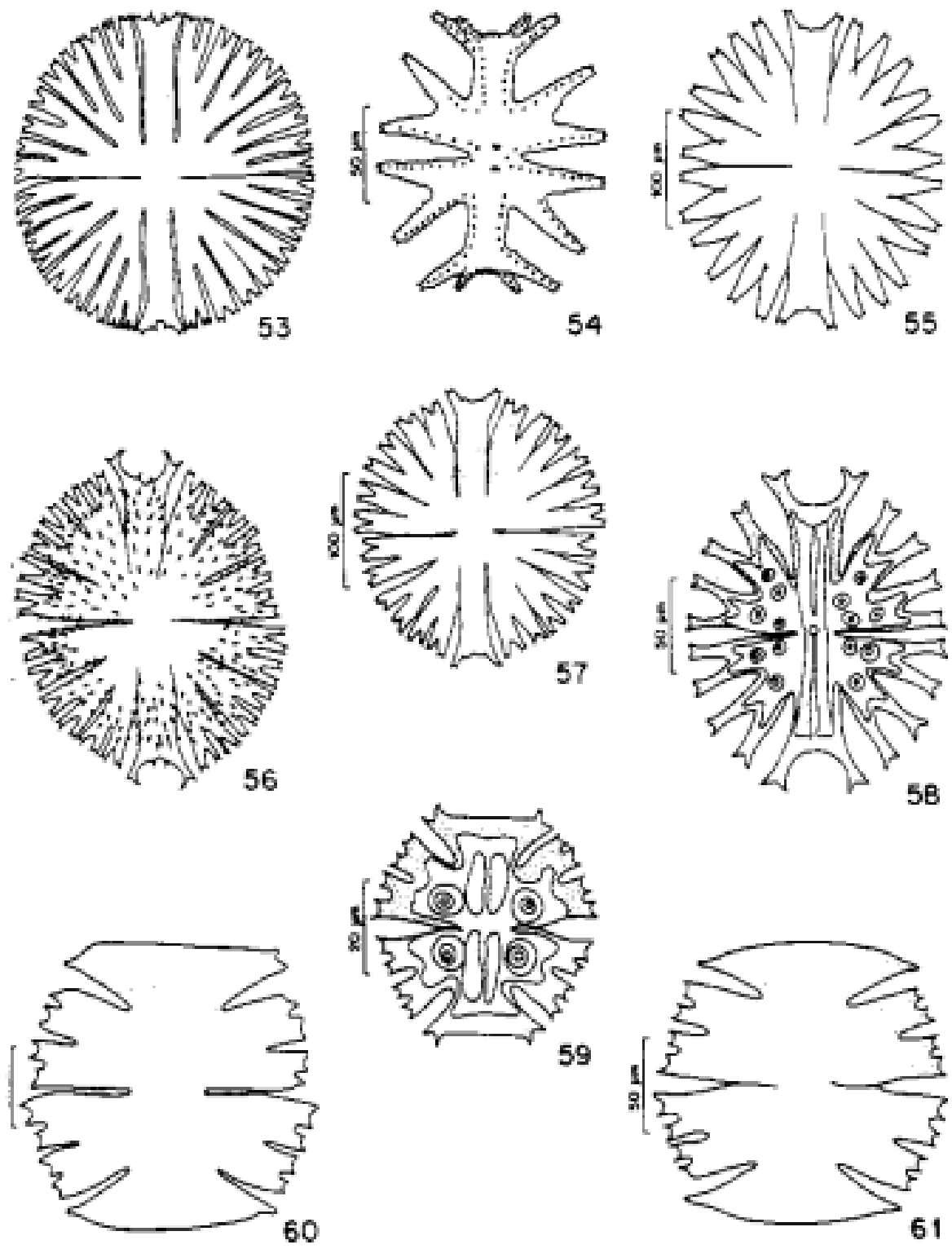

Figura 53. Micrasterias radiosa var. radiosa. Fig. 54. M. mahabuleshwarensis var. amazonensis. Fig. 55. M. torreyi var. nordstedtiana. Fig. 56. M. borgei var. multidentata. Fig. 57. M. rotata var. rotata. Fig. 58. M. furcata var. furcata. Fig. 59. M. abrupta. Fig. 60-61. M. truncata var. pusilla f. pusilla. 
Célula 1-1,1 vezes mais comprida que larga (42-48 x 40-44 $\mu \mathrm{m}$; istmo 16-18 $\mu \mathrm{m}$ larg.), semicélula subtrapeziforme, parede celular pontuada, cloroplastídio axial, pirenóides 2; vista lateral subcircular; vista apical elíptica.

Distribuição geográfica no estado do Amazonas: lago Novo Andirá (primeira citação da ocorrência da espécie).

Material examinado: SP239181, SP239193, SP239194, SP239195, SP239198, SP239210, SP239214, SP239215, SP239216, SP239217, SP239218, SP239219, SP239220, SP239221.

Cosmarium pachydermum Lundell var. pachydermum f. pachydermum (Fig. 63-64).

Nova Acta R. Soc. Scient. upsal.: 3, 8(2): 32, pl. 2, fig. 15. 1871.

Célula 1-1,3 vezes mais comprida que larga (75-132 x 75-96 $\mu \mathrm{m}$; istmo $35-43 \mu \mathrm{m}$ larg.), semicélula subsemicircular, parede celular pontuada, cloroplastídio axial, pirenóides 2; vista lateral da semicélula subcircular; vista apical da célula elíptica.

Distribuição geográfica no estado do Amazonas: lago Novo Andirá (primeira citação da ocorrência da espécie).

Material examinado: SP239181, SP239183, SP239185, SP239186, SP239187, SP239189, SP239190, SP239191, SP239192, SP239193, SP239194, SP239195, SP239196, SP239197, SP239198, SP239199, SP239200, SP239201, SP239202, SP239203, SP239204, SP239205, SP239206, SP239207, SP239210, SP239211, SP239212, SP239214, SP239215, SP239216, SP239217, SP239218, SP239219, SP239220, SP239221, SP239222.

Cosmarium granatum Brébisson ex Ralfs var. granatum f. granatum Brit. Desm. 96, pl. 32, fig. 6. 1848. (Fig. 65).

Célula 1,1-1,3 vezes mais comprida que

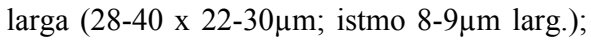
semicélula piramidal-truncada, parede celular pontuada, cloroplastídio axial, pirenóide 1; vista lateral da semicélula oval; vista apical da célula elíptica.

Distribuição geográfica no estado do Amazonas: rio Purus (Dickie 1881).

Material examinado: SP239184.

Cosmarium triangulare Borge Ark. Bot., 1: 95, pl. 3, fig. 15. 1903. (Fig. 66).

Célula tão comprida quanto larga (121-
$128 \times 112-120 \mu \mathrm{m}$; istmo $23-34 \mu \mathrm{m}$ larg.), semicélula piramidal-truncada, parede celular pontuada; vista lateral da semicélula oval; vista apical da célula elíptica, leve inflação mediana. Distribuição geográfica no estado do Amazonas: lago Novo Andirá (primeira citação da ocorrência da espécie).

Material examinado: SP239181, SP239184.

Cosmarium pseudoconnatum Nordstedt var. pseudoconnatum Vidensk. Meddr dansk naturh. Foren., 1869(14-15): 214. 1869 (1870); 1887: pl. 3, fig. 17. 1887. (Fig. 67).

Célula 1,2-1,5 vezes mais comprida que larga (37-55 x 26-34 $\mu \mathrm{m}$; istmo $25-41 \mu \mathrm{m}$ larg.), semicélula subsemicircular, parede celular pontuada, região istmial lisa, cloroplastídio axial, 4-radiado, pirenóides 4, 1 para cada projeção; vista lateral da semicélula igual à frontal; vista apical da célula circular.

Distribuição geográfica no estado do Amazonas: lago do Elias (Förster 1974), igarapé Acará, estrada Manaus-Itacoatiara, km 45 (Uherkovich \& Franken 1980).

Material examinado: SP239181, SP239184, SP239187, SP239201, SP239209, SP239210, SP239215, SP239218, SP239218, SP239220, SP239221.

Cosmarium pyramidatum Brébisson in Ralfs var. pyramidatum Brit. Desm. 94, pl. 15, fig. 4a-f. 1848. (Fig. 68).

Célula 1,5-1,6 vezes mais comprida qua larga $(54,6-74 \times 35,5-45 \mu \mathrm{m}$; istmo $12-16 \mu \mathrm{m}$ larg.), semicélula piramidal-truncada, margens laterais convexas, ápice retuso-truncado, ângulos basais arredondados, parede celular pontuada, cloroplastídio axial, pirenóides 4-5; vista lateral da semicélula oblonga; vista apical da célula elíptica.

Distribuição geográfica no estado do Amazonas: lago Novo Andirá (primeira citação da ocorrência da espécie).

Material examinado: SP239181, SP239182.

Cosmarium pyramidatum Brébisson in Ralfs var. stephani (Irénée-Marie) Krieger \& Gerloff Gatt. Cosmarium, 2: 124, pl. 25, fig. 9. 1965. (Fig. 69-70).

Célula 1,3-1,8 vezes mais comprida que larga (53-80 x 38-49 $\mu \mathrm{m}$; istmo 12-16 $\mu \mathrm{m}$ larg.). Difere da variedade-tipo da espécie por possuir 
margens laterais retas, ápice arredondadotruncado e ângulos basais sub-retangulares.

Distribuição geográfica no estado do Amazonas: lago Novo Andirá (primeira citação da ocorrência da variedade).

Material examinado: SP239181.

Cosmarium pseudopyramidatum Lundell var. rotundatum Krieger \& Gerloff Gatt. Cosmarium, 2: 129, pl. 27, fig. 3. 1965. (Fig. 71).

Célula 1,4-1,8 vezes mais comprida que larga (45-49 x 28-30 $\mu \mathrm{m}$; istmo 9-11 $\mu \mathrm{m}$ larg.), semicélula subpiramidal, parede celular pontuada, cloroplastídio axial, pirenóide 1; vista lateral da semicélula subsemicircular; vista apical da célula elíptica.

Distribuição geográfica no estado do Amazonas: lago Novo Andirá (primeira citação da ocorrência da variedade).

Material examinado: SP239181, SP239184.

Cosmarium montrealense Croasdale In Prescott et al., Syn. N.A. Desmids, 2(3): 195, pl. 171, fig. 14. 1981. (Fig. 72).

Célula 1-1,2 vezes mais comprida que

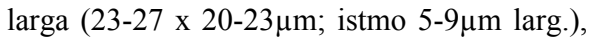
semicélula subsemicircular, parede celular lisa, cloroplastídio axial, pirenóide 1; vista lateral da semicélula subcircular; vista apical da célula elíptica.

Distribuição geográfica no estado do Amazonas: lago Novo Andirá (primeira citação da ocorrência da espécie).

Material examinado: SP239181, SP239192, SP239210, SP239215, SP239221, SP239222.

Cosmarium clepsydra Nordstedt var. bicardia (Reinsch) Croasdale Trans. Am. Microsc. Soc., 75(1): 22, pl. 11. fig. 26. 1956. (Fig. 73).

Célula 1,1-1,2 vezes mais comprida que larga (18-20 x 14-18 $\mu \mathrm{m}$; istmo $4-5 \mu \mathrm{m}$ larg.), semicélula subsemicircular, parede celular lisa, cloroplastídio axial, pirenóide 1; vista lateral da semicélula subcuneiforme, ângulos arredondados; vista apical da célula elíptica, laterais túmidas.

Distribuição geográfica no estado do Amazonas: lago Novo Andirá (primeira citação da ocorrência da espécie).

Material examinado: SP239181.
Cosmarium sublobatum (Brébisson) Archer var. brasiliense Borge Ark. Bot., 1: 101, pl. 3, fig. 34. 1903. (Fig. 74).

Célula 1,2-1,5 vezes mais comprida que

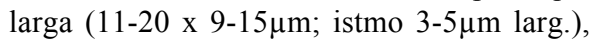
semicélula trapeziforme, parede celular lisa, cloroplastídio axial, pirenóide 1; vista lateral da semicélula oval; vista apical da célula elíptica.

Distribuição geográfica no estado do Amazonas: lago Novo Andirá (primeira citação da ocorrência da espécie).

Material examinado: SP239184.

Cosmarium rectangulare Grunov var. hexagonum (Elfving) West \& West Monog. Brit. Desm., 3: 56, pl. 70, fig. 4. 1908. (Fig. 75-77).

Célula 1-1,1 vezes mais comprida que

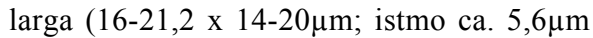
larg.), semicélula hexagonal, parede celular lisa; vista lateral da semicélula subcircular; vista apical da célula elíptica.

Distribuição geográfica no estado do Amazonas: lago Novo Andirá (primeira citação da ocorrência da espécie).

Material examinado: SP239181, SP239184, SP239187, SP239190, SP239202.

Cosmarium trilobulatum Reinsch var. trilobulatum f. trilobulatum Acta Soc. Senckenb., 6: 118, pl. 22 AII, fig. 1-6. 1867. (Fig. 78-79).

Célula 1,1-1,3 vezes mais comprida que

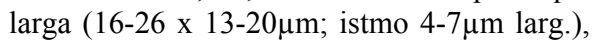
semicélula subtrapeziforme, parede celular pontuada, cloroplastídio axial, pirenóide 1; vista lateral da semicélula subcircular; vista apical da célula elíptica.

Distribuição geográfica no estado do Amazonas: lago Novo Andirá (primeira citação da ocorrência da variedade típica da espécie).

Material examinado: SP239181, SP239210, SP239216, SP239217, SP239218, SP239219.

Cosmarium fontigenum Nordstedt var. pseudofontigenum (Gutwinski) West \& West Monogr. Brit. Desm., 2: 148. 1905. (Fig. 80).

Célula $1-1,1$ vezes mais comprida que

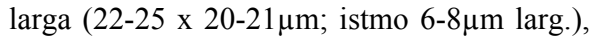
semicélula trapeziforme, parede celular lisa, cloroplastídio axial, pirenóide 1; vista lateral da semicélula subcircular; vista apical da célula elíptica. 
Distribuição geográfica no estado do Amazonas: lago Novo Andirá (primeira citação da ocorrência da espécie).

Material examinado: SP239221.

Cosmarium regnellii Wille var. regnellii K. svenska VetenskAkad. Handl., 8(18): 16, pl. 1, fig. 34. 1884. (Fig. 81).

Célula $1-1,3$ vezes mais comprida que

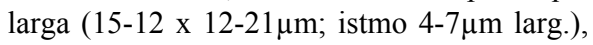
semicélula hexagonal, parede celular lisa, cloroplastídio axial, pirenóide 1; vista lateral da semicélula subcircular; vista apical da célula oblonga.

Distribuição geográfica no estado do Amazonas: igarapé Acará, estrada ManausItacoatiara (Uherkovich \& Franken 1980).

Material examinado: SP239181, SP239219, SP239221.

Cosmarium exiguum Archer var. exiguum f. exiguum Proc. Nat. Hist. Soc. Dublin, 4(1): 49, pl. 1, fig. 32-33. 1864. (Fig. 82).

Célula 2-2,2 vezes mais comprida que

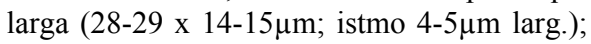
semicélula subquadrática, parede celular granulosa, cloroplastídio axial, pirenóide 1; vista lateral da semicélula oblonga; vista apical da célula elíptica.

Distribuição geográfica no estado do Amazonas: lago Novo Andirá (primeira citação da ocorrência da espécie).

Material examinado: SP239181, SP239184.

Cosmarium humile (Gay) Nordstedt var. glabrum Gutwinski Nuova Notarisia, 3: 21. 1892. (Fig. 83).

Célula 1-1,3 vezes mais comprida que

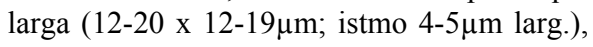
semicélula sub-retangular, parede celular lisa, cloroplastídio axial, pirenóide 1; vista lateral da semicélula subcircular; vista apical da célula elíptica, protuberância mediana em ambos os lados.

Distribuição geográfica no estado do Amazonas: lago Novo Andirá (primeira citação da ocorrência da espécie).

Material examinado: SP239181.

Cosmarium levinotabile Croasdale var. heterocrenatum (West \& West) Croasdale In Prescott et al., Syn. N.A. Desmids, 2(3): 173, pl. 198, fig. 6-8. 1981. (Fig. 84).
Célula 1,3-1,4 vezes mais comprida que

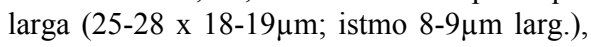
semicélula trapeziforme, parede celular pontuada, cloroplastídio axial, pirenóide 1; vista lateral da semicélula oblonga; vista apical da célula elíptica.

Distribuição geográfica no estado do Amazonas: lago Novo Andirá (primeira citação da ocorrência da espécie).

Material examinado: SP239181.

Cosmarium denticulatum Borge var. ovale Grönblad Acta Soc. Sci. fenn.: sér. B, 2(6): 17, pl. 5, fig. 103. 1945. (Fig. 85).

Célula 1,3-1,5 vezes mais comprida que larga (198-215 x 141-165 $\mu \mathrm{m}$; istmo $39-46 \mu \mathrm{m}$ larg.), semicélula piramidal, parede celular com espinhos, região central pontuada e espinhos esparsos.

Distribuição geográfica no estado do Amazonas: lago Novo Andirá (primeira citação da ocorrência da variedade).

Material examinado: SP239181, SP239187.

Cosmarium margaritatum (Lundell) Roy \& Bisset var. margaritatum f. minor (Boldt) West \& West J. Bot., 35: 121. 1897. (Fig. 86).

Célula ca. 1,2 vezes mais comprida que larga (50,3-55,4 x 40,8-41,6 $\mu \mathrm{m}$; istmo 12,8$13,8 \mu \mathrm{m}$ larg.). Difere da forma típica pelas menores dimensões celulares.

Distribuição geográfica no estado do Amazonas: lago Novo Andirá (primeira citação da ocorrência da forma).

Material examinado: SP239181, SP239184, SP239202, SP239205, SP239210, SP239212, SP239214.

Cosmarium margaritatum (Lundell) Roy \& Bisset var. margaritatum f. margaritatum J. Bot., 24: 194. 1885. (Fig. 87).

Célula ca. 1 vez mais comprida que larga (72,9-77,6 x 70-71,3 $\mu \mathrm{m}$, istmo $21-25,5 \mu \mathrm{m}$ larg.), semicélula oblongo-elíptica, parede celular granulosa, cloroplastídio axial, pirenóides 2; vista lateral da semicélula subcircular; vista apical da célula oblonga.

Distribuição geográfica no estado do Amazonas: igarapé Iaiana, rio Iá (Förster 1963).

Material examinado: SP239181, SP239186, SP239188, SP239189, SP239191, SP239192, SP239193, SP239195, SP239197, 

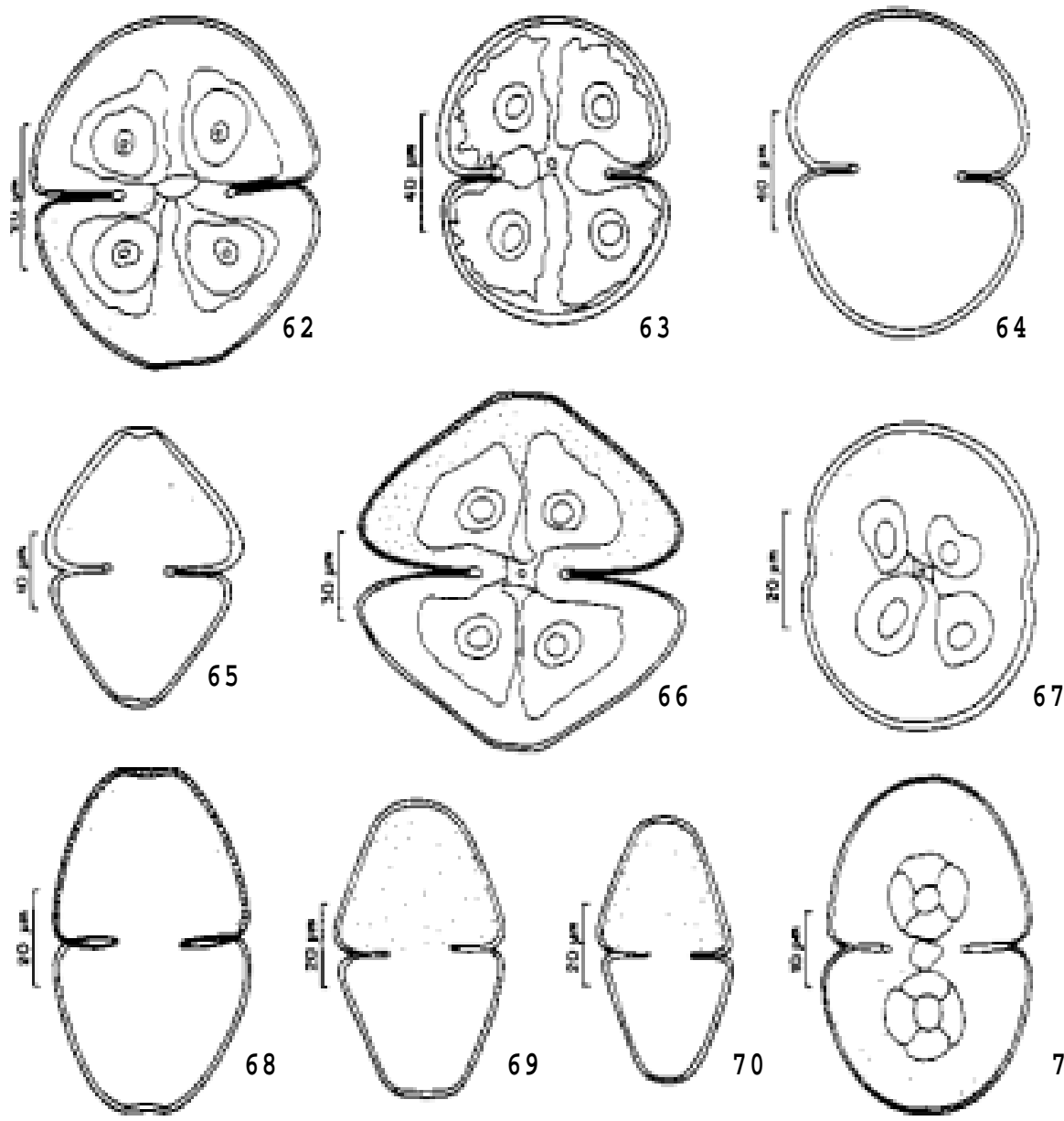

71
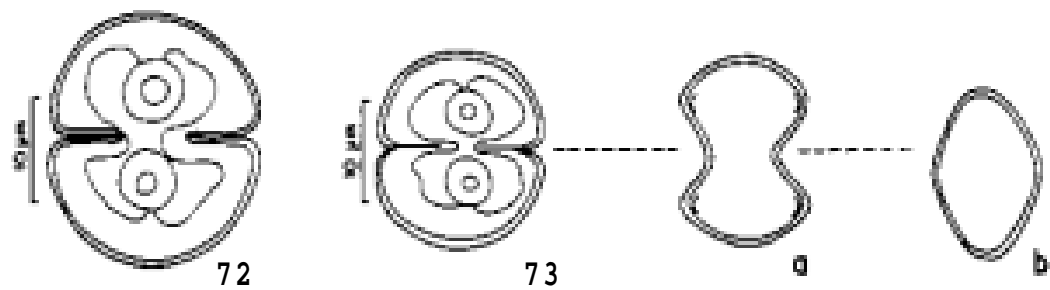

Figura 62. Cosmarium candianum var. candianum f. candianum. Fig. 63-64. C. pachydermum var. pachydermum f. pachydermum. Fig. 65. C. granatum var. granatum f. granatum. Fig. 66. C. triangulare. Fig. 67. C. pseudoconnatum var. pseudoconnatum. Fig. 68. C. pyramidatum var. pyramidatum. Fig. 69-70. C. pyramidatum var. stephani. Fig. 71. C. pseudopyramidatum var. rotundatum. Fig. 72. C. montrealense. Fig. 73. C. clepsydra var. bicardia; a: vista lateral; b: vista apical. 

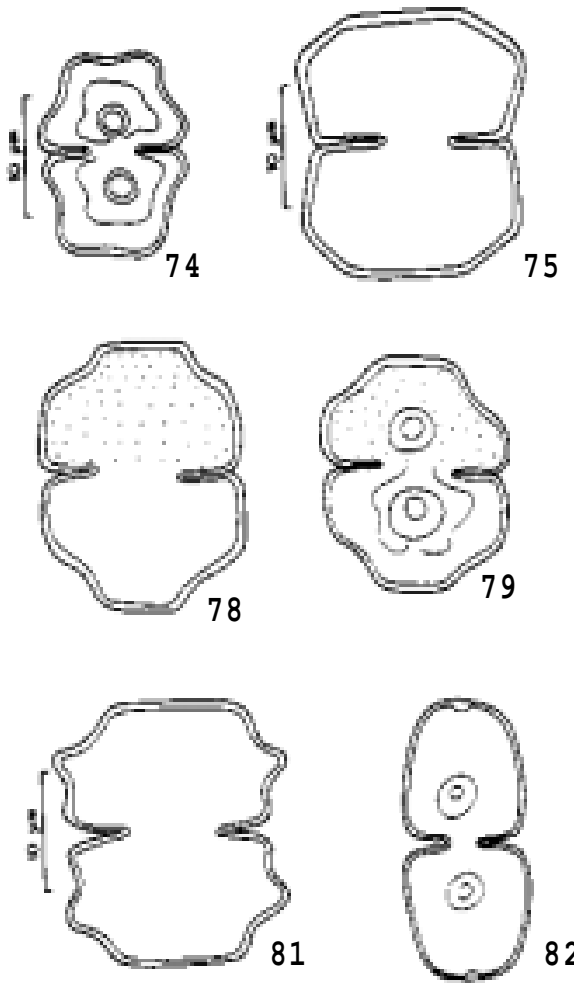
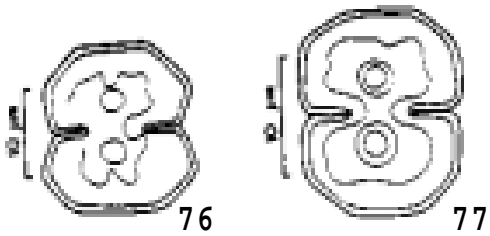

75

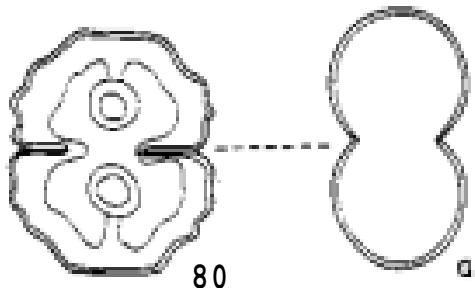

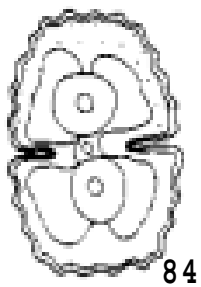
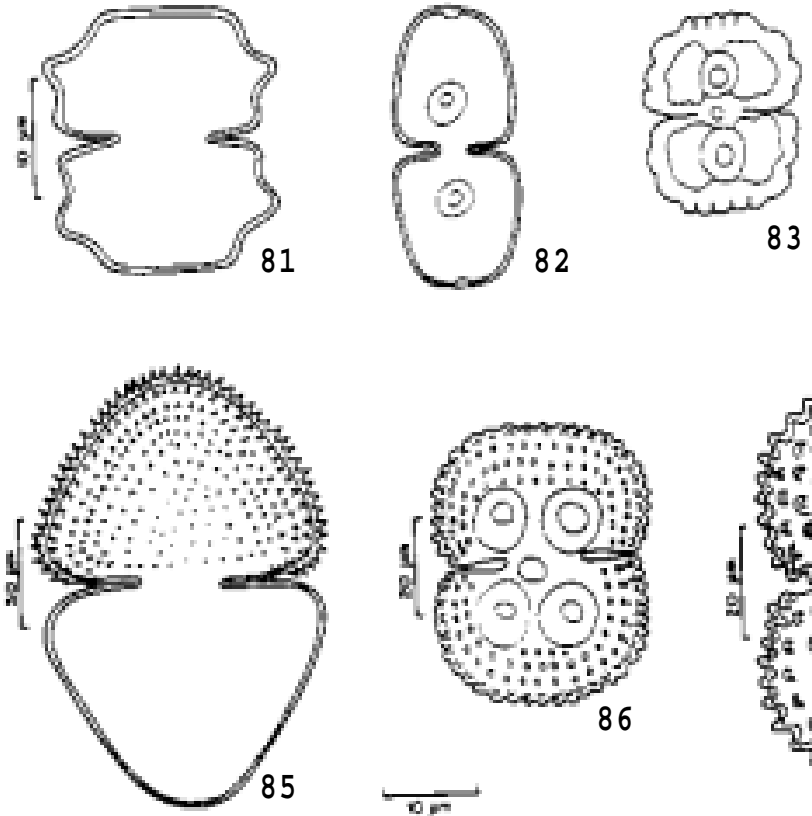

83

82
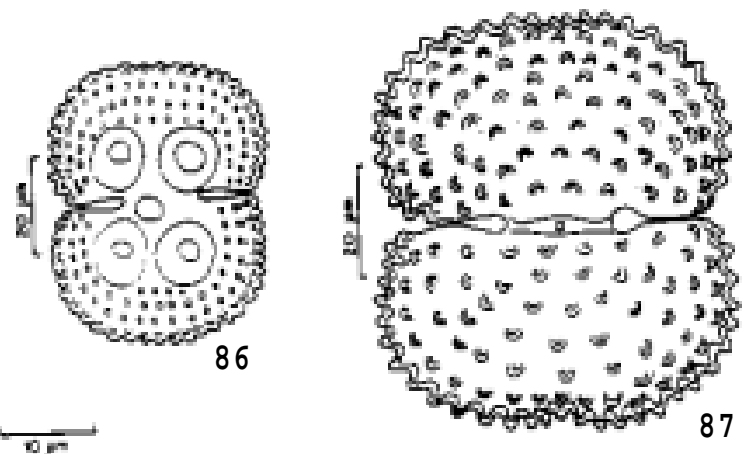

Figura 74. Cosmarium sublobatum var. brasiliense. Fig. 75-77. C. rectangulare var. hexagonum. Fig. 78-79. C. trilobulatum var. trilobulatum f. trilobulatum. Fig. 80. C. fontigenum var. pseudofontigenum; a: vista lateral. Fig. 81. C. regnellii var. regnellii. Fig. 82. C. exiguum var. exiguum f. exiguum. Fig. 83. C. humile var. glabrum. Fig. 84. C. levinotabile var. heterocrenatum. Fig. 85. C. denticulatum var. ovale. Fig. 86. C. margaritatum var. margaritatum f. minor. Fig. 87. C. margaritatum var. margaritatum f. margaritatum. 
SP239198, SP239199, SP239202, SP239203, SP239204, SP239206, SP239207, SP239208, SP239209, SP239210, SP239211, SP239212, SP239213, SP239214, SP239215, SP239216, SP239217, SP239218, SP239219, SP239220, SP239221, SP239222.

Cosmarium quadrum Lundell var. quadrum Nova Acta R. Soc. Scient. upsal.: sér. 3, 8(2): 25, pl. 2, fig. 11. 1871. (Fig. 88).

Célula ca. 1 vez mais comprida que larga (52-56 x ca. $48 \mu \mathrm{m}$; istmo ca. $19 \mu \mathrm{m}$ larg.), semicélula sub-retangular, parede celular granulosa, cloroplastídio axial, pirenóides 2; vista lateral da semicélula subcircular; vista apical da célula oblonga.

Distribuição geográfica no estado do Amazonas: lago Novo Andirá (primeira citação da ocorrência da espécie).

Material examinado: SP239193, SP239198, SP239202, SP239208, SP239215, SP239216.

Cosmarium dichondrum West \& West var. tumidum Borge Ark. Bot., 1: 89, pl. 2, fig. 19. 1903. (Fig. 89).

Célula 1-1,1 vezes mais comprida que larga (20-24 x 19-21 $\mu \mathrm{m}$; istmo 5-8 $\mu \mathrm{m}$ larg.); semicélula oblongo-elíptica, parede celular granulosa, 3 grânulos proeminentes, 1 central, 2 subapicais, cloroplastídio axial, pirenóide 1; vista lateral da semicélula subcircular, 2 grânulos proeminentes, 1 de cada lado, próximo ao ápice; vista apical da célula elíptica, 2-3 grânulos proeminentes na porção mediana das margens.

Distribuição geográfica no estado do Amazonas: lago Novo Andirá (primeira citação da ocorrência da espécie).

Material examinado: SP239181.

Cosmarium punctulatum Brébisson var. punctulatum f. punctulatum Mém. Soc. Imp. Sci. nat. Cherbourg ,4: 129, pl. 1, fig. 16. 1856. (Fig. 90).

Célula tão comprida quanto larga (22-30

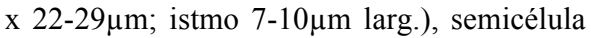
oblongo-trapeziforme, parede celular granulosa, cloroplastídio axial, pirenóide 1; vista lateral da semicélula subcircular; vista apical da célula elíptica.

Distribuição geográfica no estado do Amazonas: lago Novo Andirá (primeira citação da ocorrência da espécie).

\section{SP239192.}

Material examinado: SP239181,

Cosmarium sp. 1 (Fig. 91-92).

Célula 1-1,1 vezes mais comprida que larga, constrição mediana profunda, seno mediano linear, fechado $(20-32 \times 20-29 \mu \mathrm{m}$; istmo $6-10 \mu \mathrm{m}$ larg.), semicélula oblongotrapeziforme, margens laterais e apical onduladas, laterais convexas, convergindo ligeiramente para o ápice truncado, ângulos basais e apicais arredondados, parede celular densamente granulosa, grânulos sólidos, tamanho uniforme, cloroplastídio axial, pirenóides 2; vista lateral da semicélula subcircular; vista apical da célula elíptica.

Material examinado: SP239181, SP239192.

Comentários: Os atuais exemplares lembram, morfologicamente, os de $C$. punctulatum Brébisson var. punctulatum, $C$. blyttii Wille var. blyttii e C. subcrenatum Hantzsch. Contudo, as três espécies antes mencionadas apresentam um pirenóide por semicélula, diferindo de Cosmarium sp. 1 que apresenta dois. Além disso, há diferenças significativas nas vistas apical da célula e lateral da semicélula. Diante de tais considerações, não foi possível enquadrar Cosmarium sp. 1 em quaisquer dessas circunscrições, nem em qualquer outra das atuais espécies do gênero. Muito provavelmente se trate de uma espécie nova, cuja descrição formal e proposição da novidade só será possível ante o exame de maior número de indivíduos.

Cosmarium sp. 2 (Fig. 93-94).

Célula 1-1,1 vezes mais comprida que larga, constrição mediana profunda, seno mediano linear, fechado (40-42 x 35-38 $\mu \mathrm{m}$; istmo $13-14 \mu \mathrm{m}$ larg.), semicélula semicircular, margens laterais e apical onduladas, 2 séries de ondulações intramarginais, margens laterais convexas, ápice arredondado, ângulos basais e apicais arredondados, parede celular densamente granulosa, grânulos sólidos, uniformes, cloroplastídio axial, pirenóides 2; vista lateral da semicélula semicircular; vista apical da célula oblongo-elíptica, ápices 4ondulados, granulados, 2-3 séries de ondulações em cada ápice.

Material examinado: SP239181, SP239218. 
Comentários: $\mathrm{O}$ conjunto das características morfológicas e métricas apresentadas pelos indivíduos da população ora estudada, torna-os distintos da espécie mais próxima, Cosmarium obtusatum Schmidle em Prescott et al. (1981) e Croasdale \& Flint (1988). Estes autores documentaram para $C$. obtusatum medidas celulares de 42-60(-80) x $37-50(-54) \mu \mathrm{m}$, vista lateral da semicélula elíptica e parede celular pontuada. Os atuais exemplares apresentaram medidas celulares menores, vista lateral subcircular e parede celular granulosa o que, a nosso ver, justifica não identificá-la com nenhuma das espécies ora conhecidas. Parece tratar-se de uma espécie nova e o exame de maior número de exemplares será imprescindível para tal definiç̧ão.

Cosmarium comissurale Brébisson ex Ralfs var. crassum Nordstedt f. crassum Vidensk. Meddr dansk naturh. Foren., 1869(1415): 213. 1869 (1870); 1887: pl. 3, fig. 19. 1887. (Fig. 95).

Célula $0,8-1$ vez mais comprida que larga (28-34 x 27-34 $\mu \mathrm{m}$; istmo $8-10 \mu \mathrm{m}$ larg.), semicélula sub-reniforme, parede celular granulosa, pontuada entre os grânulos; vista apical da célula elíptica, margens laterais intumescidas na porção mediana, constrita próximo dos ápices amplamente arredondados, inflados.

Distribuição geográfica no estado do Amazonas: lago Novo Andirá (primeira citação da ocorrência da espécie).

Material examinado: SP239182, SP239184.

Cosmarium regnesi Reinsch var. montanum Schmidle Hedwigia, 34: 74, pl. 1, fig. 9. 1895. (Fig. 96-97).

Célula tão comprida quanto larga (9-12 x 9-12 $\mu \mathrm{m}$; istmo $4-5 \mu \mathrm{m}$ larg.), semicélula subretangular, margens laterais e apical denteadas, parede celular lisa, cloroplastídio axial, pirenóide 1; vista apical da célula elíptica, 2 dentes apicais, 3 protuberâncias de cada lado.

Distribuição geográfica no estado do Amazonas: lago Novo Andirá (primeira citação da ocorrência da variedade).

Material examinado: SP239181.

Cosmarium excavatum Nordstedt var. excavatum Vidensk. Meddr dansk naturh. Foren., 1869(14-15): 214. 1869 (1870); 1887: pl. 3, fig. 25. 1887. (Fig. 98).

Célula 1,6-2,1 vezes mais comprida que larga (25-30 x 14-18 $\mu \mathrm{m}$; istmo $10-11 \mu \mathrm{m}$ larg.), semicélula subcircular, parede celular granulosa, cloroplastídio axial, pirenóide 1; vista lateral da semicélula similar à frontal; vista apical da célula circular.

Distribuição geográfica no estado do Amazonas: lago Novo andirá (primeira citação da ocorrência da espécie).

Material examinado: SP239181.

Octacanthium (Hansgirg) Compère

Octacanthium mucronulatum (Nordstedt) Compère var. mucronulatum Beih. Nova Hedwigia, 112: 505, fig. 8-9. 1996. (Fig. 99).

Célula $0,7-0,8$ vezes mais comprida que larga, sem considerar os processos (26-40,2 x $30-50,1 \mu \mathrm{m}$; istmo $10-14 \mu \mathrm{m}$ larg.), semicélula elíptico-fusiforme, margem superior convexa, margens laterais levemente convexas, ângulos com ou sem espinhos reduzidos a mucros, parede celular finamente pontuada; vista apical da célula elíptico-fusiforme, 1 espinho curto em cada pólo.

Distribuição geográfica no estado do Amazonas: lago Novo Andirá (primeira citação da ocorrência da espécie).

Material examinado: SP239181, SP239215.

\section{Staurodesmus Teiling}

Chave artificial para identificação das espécies, variedades e formas taxonômicas de Staurodesmus

1. Semicélula de contorno transversalmente elíptico em vista frontal.

2. Espinhos laterais dirigidos horizontalmente S. brevispina var. brevispina

2. Espinhos laterais convergentes entre si.

3. Espinhos longos ( $>5 \mu \mathrm{m}$ compr.) $S$. convergens var. laportei

3. Espinhos curtos $(<5 \mu \mathrm{m}$ compr.).

4. Vista apical da célula elíptica (biangular) S. lobatus var. ellipticus f. minor

4. Vista apical da célula triangular.

5. Célula 25-33 $\mu \mathrm{m}$ compr. S. dickiei var. dickiei

5. Célula 50-67,5 $\mu \mathrm{m}$ compr. S. dickiei var. maximus

1. Semicélula de contorno 
obtrapeziforme ou obtriangular em vista frontal.

6. Células $20-27 \mu \mathrm{m}$ compr., istmo alongado S. cuspidatus var. curvatus f. curvatus

6. Células $10-15 \mu \mathrm{m}$ compr., istmo não alongado. Staurodesmus sp.

Staurodesmus cuspidatus (Brébisson) Teiling var. curvatus (W. West) Teiling f. curvatus Ark. Bot.: sér. 2, 6(11): 535, pl. 9, fig. 12, pl. 10, fig. 1-4. 1967. (Fig. 100-101).

Célula 1-1,6 vezes mais comprida que larga, sem considerar os espinhos (20-27 x 15$25 \mu \mathrm{m} ; 35-48 \mu \mathrm{m}$ larg. com espinhos; istmo 5$7 \mu \mathrm{m}$ larg.), semicélula obtriangular, ângulos apicais ornados com 1 espinho longo, robusto, divergente, parede celular lisa; vista apical da célula triangular, ângulos atenuados em espinho longo, robusto, margens retusas entre os ângulos.

Distribuição geográfica no estado do Amazonas: reservatório de Balbina (Bittencourt-Oliveira 1993c), lago do Castanho (Uherkovich \& Schmidt 1974).

Material examinado: SP239181, SP239182, SP239183, SP239184, SP239195.

Staurodesmus sp. (Fig. 102).

Célula 1-1,2 vezes mais comprida que larga, sem considerar os espinhos (10-15 x 10$12 \mu \mathrm{m}$ larg. sem espinhos; $13-21 \mu \mathrm{m}$ larg. com espinhos; istmo 6-10 $\mu \mathrm{m}$ larg.), constrição mediana rasa, seno mediano aberto, obtuso, semicélula obtrapeziforme, margem apical truncada a levemente convexa, lisa, laterais retas, às vezes ligeiramente 2-onduladas, divergindo para o ápice, ângulos apicais com 1 espinho curto, delgado, divergente; parede celular lisa; vista apical da célula triangular, ângulos inflados, ornados com 1 espinho curto.

Material examinado: SP239181, SP239182, SP239184.

Comentários: Os exemplares ora examinados poderiam ser identificados tanto como Staurodesmus o'mearii (Archer) Teiling quanto como Staurodesmus pterosporus (Lundell) Bourrelly. No entanto, segundo Teiling (1967) estas duas espécies são dificilmente separáveis apenas com a observação da expressão morfológica das células vegetativas. A diferença entre ambas é feita através dos zigósporos, que são esféricos em
S. o'mearii e em forma de paralelepípedo em S. pterosporus. Como não observamos zigósporos na população estudada, não foi possível a identificação em nível específico.

Staurodesmus lobatus (Börgesen) Bourrelly var. ellipticus (Fritsch \& Rich) Teiling f. minor (G.M. Smith) Teiling Ark. Bot.: sér. 2, 6(11): 586, pl. 24, fig. 8. 1967. (Fig. 103).

Célula 1-1,3 vezes mais comprida que larga, sem considerar os espinhos (29-36 x 23$34 \mu \mathrm{m} ; 28-37 \mu \mathrm{m}$ larg. com espinhos; istmo 8,7$9,6 \mu \mathrm{m}$ larg.), semicélula transversalmente oblongo-elíptica, ângulos arredondados, ornados com 1 espinho curto, ligeiramente convergente, parede celular lisa; vista lateral da semicélula subcircular; vista apical da célula elíptica, 1 espinho curto em cada ápice.

Distribuição geográfica no estado do Amazonas: rios Maués-assu, rio Apoquitaua, rio Canumã (Förster 1974), lago São Sebastião (Martins 1980a), reservatório de Balbina (Bittencourt-Oliveira 1990b), rio Negro (Uherkovich \& Rai 1979).

Material examinado: SP239182, SP239183, SP239184, SP239187.

Staurodesmus brevispina (Brébisson) Croasdale var. brevispina Trans. Am. microsc. Soc., 76(2): 122, pl. 3, figs. 47-48. 1957. (Fig. 104).

Célula 1-1,1 vezes mais comprida que larga, sem considerar os espinhos (30-35 x 26$32 \mu \mathrm{m}$ sem espinhos, $29-34 \mu \mathrm{m}$ larg. com espinhos; istmo 8-9 $\mu$ m larg.), semicélula transversalmente elíptica, ângulos arredondados, ornados com 1 espinho curto, dirigido horizontalmente, parede celular lisa; vista apical da célula triangular, margens côncavas, ângulos inflados, ornados com 1 espinho curto.

Distribuição geográfica no estado do Amazonas: reservatório de Balbina (Bittencourt-Oliveira 1993c):

Material examinado: SP239181, SP239187, SP239194.

Staurodesmus convergens (Ehrenberg) Teiling var. laportei Teiling Ark. Bot.: sér. 2, 6(11): 588, pl. 25, fig. 4-7, pl. 26, fig. 1-3. 1967. (Fig. 105).

Célula 1,1-1,2 vezes mais comprida que larga, sem considerar os espinhos (58-85 $\mathrm{x}$ 46-75 $\mu \mathrm{m}$ sem espinhos, $78-110 \mu \mathrm{m}$ larg. 

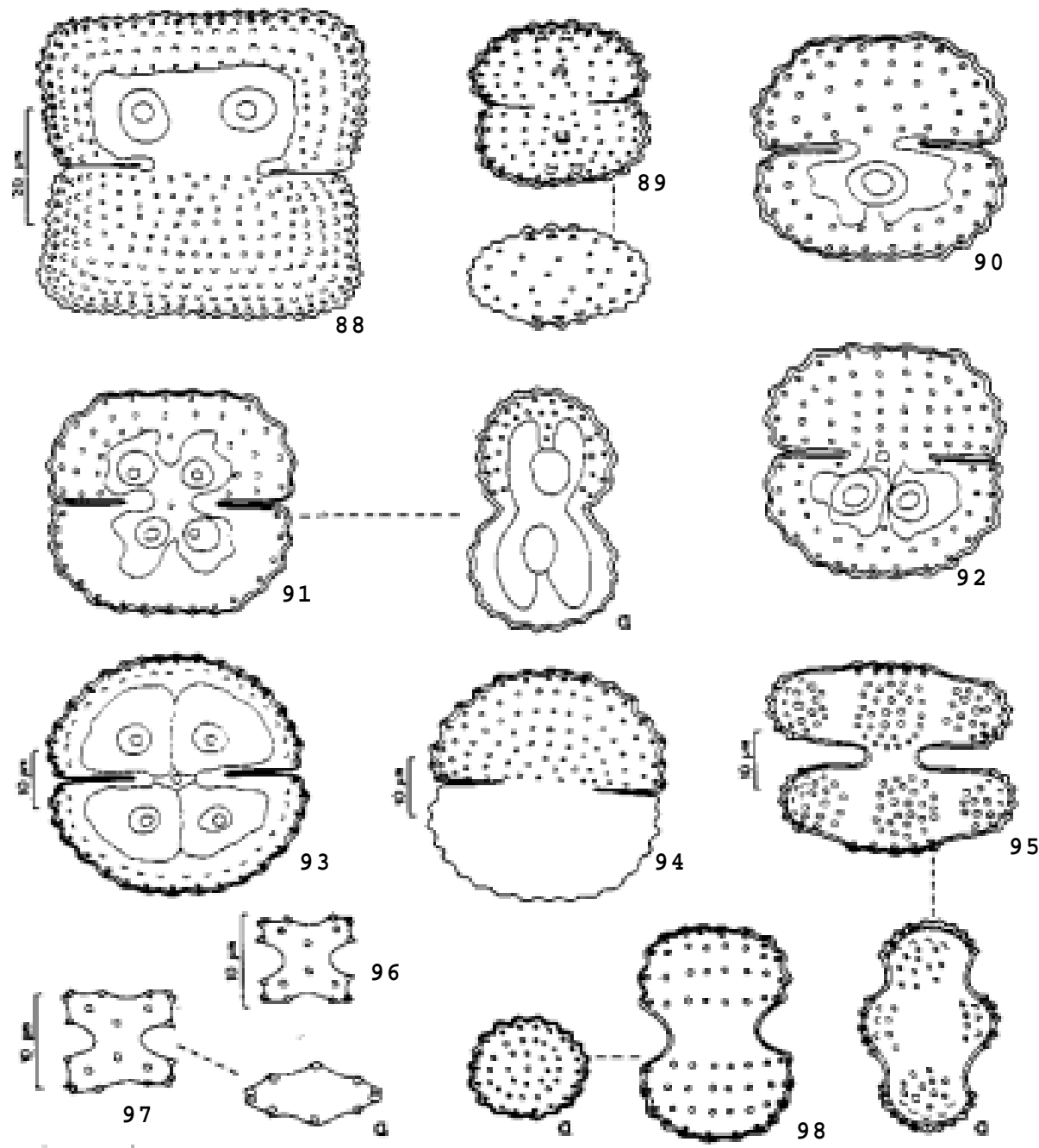

106

Figura 88. Cosmarium quadrum var. quadrum. Fig. 89. C. dichondrum var. tumidum; a: vista apical. Fig. 90. C. punctulatum var. punctulatum f. punctulatum. Fig. 91-92. Cosmarium sp. 1; a: vista lateral. Fig. 93-94. Cosmarium sp. 2. Fig. 95. C. comissurale var. crassum f. crassum; a: vista apical. Fig. 96-97. C. regnesi var. montanum; a: vista apical. Fig. 98. C. excavatum var. excavatum; a: vista apical. 

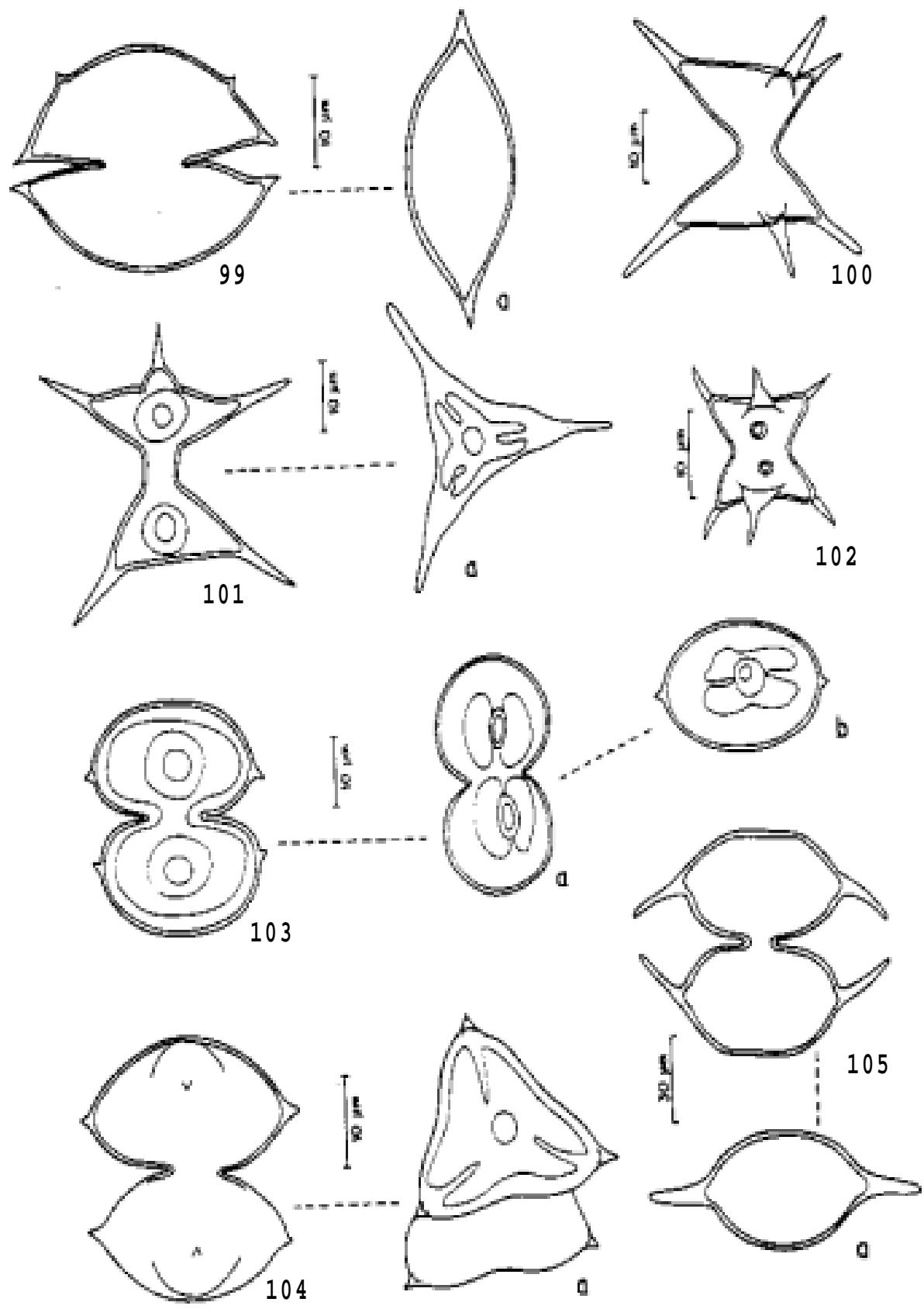

Figura 99. Octacanthium mucronulatum var. mucronulatum; a: vista apical. Fig. 100-101. Staurodesmus cuspidatus var. curvatus f. curvatus; a: vista apical. Fig. 102. Staurodesmus sp. Fig. 103. S. lobatus var. ellipticus f. minor; a: vista lateral; b: vista apical. Fig. 104. S. brevispina var. brevispina; a: vista apical. Fig. 105. S. convergens var. laportei; a: vista apical. 
com espinhos; istmo 10-20 $\mu \mathrm{m}$ larg.), semicélula transversalmente elíptica, ângulos arredondadas no terço mediano da semicélula, ornados com 1 espinho longo ( $>5$ um compr.), robusto, convergente, parede celular lisa; vista apical da célula elíptica, 1 espinho longo, robusto em cada ápice.

Distribuição geográfica no estado do Amazonas: rio Maués-mirim, rio Mauésassu (Förster 1974), lago do Castanho (Uherkovich \& Schmidt 1974), rio Negro (Uherkovich \& Rai 1979), rio Maués-assu (Uherkovich 1981).

Material examinado: SP239181, SP239187.

Staurodesmus dickiei (Ralfs) Lillieroth var. dickiei Acta Limnol., 3: 264. 1950. (Fig. 106).

Célula 1-1,1 vezes mais comprida que larga, sem considerar os espinhos (25-33 x 22-25 $\mu \mathrm{m} ; 26-30 \mu \mathrm{m}$ larg. com espinhos; istmo $7-10 \mu \mathrm{m}$ larg.), semicélula transversalmente elíptica, ângulos apicais ornados com 1 espinho curto, robusto, convergente, parede celular lisa; vista apical da célula triangular, ângulos ligeiramente inflados, 1 espinho curto, margens retusas entre os ângulos.

Distribuição geográfica no estado do Amazonas: lago Novo Andirá (primeira citação da ocorrência da variedade-típica).

Material examinado: SP239181, SP239214, SP239218.

Staurodesmus dickiei (Ralfs) Lillieroth var. maximus (West \& West) Thomasson Acta Phytogeogr. Suec., 47: pl. 34, fig. 13. 1963. (Fig. 107-108).

Célula 0,8-1 vez mais comprida que larga, sem considerar os espinhos (50-67,5 x $45-70 \mu \mathrm{m}$; istmo $10-14 \mu \mathrm{m}$ larg.).

Distribuição geográfica no estado do Amazonas: rio Negro (Uherkovich \& Rai 1979).

Material examinado: SP239181, SP239214.

Comentários: Difere da variedade tipo pelas medidas celulares maiores.

Xanthidium Ehrenberg

Xanthidium trilobum Nordstedt Vidensk. Meddr dansk naturh. Foren., 1869(14-15): 230. 1869 (1870); 1887: pl. 3, fig. 35 a-c. 1887. (Fig. 109).
Célula 1,1-1,2 vezes mais comprida que larga, sem considerar os processos (80118 × 74-105 $\mu \mathrm{m} ; 100-160 \times 90-140 \mu \mathrm{m}$ com processos; istmo $20-29 \mu \mathrm{m}$ larg.), semicélula sub-hexagonal, ângulos projetados em processos cilíndricos, curtos, 2-espinados, parede celular lisa ou finamente pontuada; vista apical da célula romboidal, 1 projeção lateral mediana 3-lobulada, ângulos projetados, ornados com 1 espinho curto, robusto, divergentes entre si nas 2 semicélulas.

Distribuição geográfica no estado do Amazonas: rio Abacaxis, rio Maués-assu (Förster 1974), lagos Cristalino, lago São Sebastião (Martins 1980a), reservatório de Balbina (Bittencourt-Oliveira 1993c), rio Negro (Uherkovich 1976), lago Calado (Uherkovich 1981).

Material examinado: SP239181, SP239214, SP239216.

\section{Staurastrum Meyer}

Chave artificial para identificação das espécies, variedades e formas taxonômicas de Staurastrum

1. Células com processos ou espinhos angulares.

2. Parede celular lisa.

3. Processos angulares longos S. volans var.

\section{fuquenense}

3. Processos angulares curtos ou apenas espinhos divergentes ou superpostos.

4. Semicélula obtrapeziforme ou subcuneiforme.

5. Ângulos com espinhos.

6. Semicélula obtrapeziforme, 2 espinhos divergentes .............................. $S$. curvimarginatum

6. Semicélula subcuneiforme, 3 espinhos robustos direcionados obliqüamente para baixo .......................... S. trifidum var. inflexum

5. Ângulos com processos.

7. Vista apical 6-angular, ângulos estendidos em processos 3-espinados S. subpolymorphum

7. Vista apical 5-angular, ângulos emarginados com 2 pares de espinhos superpostos ........................... S. quadrangulare var. contectum

4. Semicélula sub-retangular a subelíptica. 
8. Vista apical 3-angular, ângulos com processos 2-furcados .. $S$. quadricornutum

8. Vista apical 4-angular, ângulos emarginados com 2 pares de espinhos superpostos .................... S. quadrangulare var. quadrangulare

2. Parede celular com espinhos ou grânulos, às vezes restritos aos processos.

9. Indivíduos sem processos angulares, ângulos ornados com 2 espinhos longos, robustos S. minnesotense var. minnesotense

9. Indivíduos com processos angulares.

10. Processos angulares curtos S. disputatum var. sinense

10. Processos angulares longos.

11. Semicélula com 8 verrugas apicais intramarginais;

8 processos angulares com espinhos S. rotula

11. Semicélula sem verrugas apicais; 36 processos angulares com grânulos.

12. Indivíduos com 3 processos angulares; vista apical 3-angular tetracerum f. trigona

12. Indivíduos com 6 processos angulares; vista apical 6-angular S. margaritaceum var. margaritaceum angulares.

1. Células sem processos ou espinhos

13. Parede celular granulosa S. punctulatum var. punctulatum f. punctulatum

13. Parede celular lisa ou finamente pontuada.

14. Semicélula semicircular S. orbiculare var.

orbiculare f. orbiculare

14. Semicélula transversalmente elíptica.

15. Célula $31-35 \mu \mathrm{m}$ compr.; margem apical convexa ou levemente côncava S. muticum var. muticum

15. Célula $17-18 \mu \mathrm{m}$ compr.; margem apical achatada ..................................... $S$. muticum var. depressum
Staurastrum orbiculare (Ehrenberg) Ralfs var. orbiculare f. orbiculare Brit. Desm. 125, pl. 21, fig. 5. 1848. (Fig. 110111).

Célula 1-1,2 vezes mais comprida que larga (32-45 x 32-40 $\mu \mathrm{m}$; istmo 11-15 $\mu \mathrm{m}$ larg.), semicélula subcircular; parede celular finamente pontuada; vista apical da célula triangular, ângulos arredondados, margens laterais retas, às vezes levemente retusas.

Distribuição geográfica no estado do Amazonas: lago Novo Andirá (primeira citação da ocorrência da variedade típica).

Material examinado: SP239181.

Staurastrum muticum (Brébisson) Ralfs var. muticum Brit. Desm. 125, pl. 21, fig. 4, pl. 34, fig. 13. 1848. (Fig. 112).

Célula 1-1,1 vezes mais comprida que

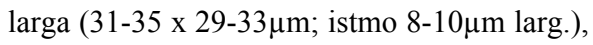
semicélula transversalmente elíptica ou subreniforme, margem apical convexa ou levemente côncava, parede celular lisa; vista apical da célula triangular, ângulos amplamente arredondados, margens côncavas entre os ângulos.

Distribuição geográfica no estado do Amazonas: rios Maués-assu, rio Mauésmirim, igarapé Laguinho (rio Maués-assu) (Förster 1974), rio Unini (Uherkovich \& Rai 1979).

Material examinado: SP239217, SP239181 e SP239222.

Staurastrum muticum (Brébisson) Ralfs var. depressum Nordstedt Point. Skandib. Växt. 4: 27. 1880. (Fig. 113).

Célula 0,7-0,8 vez mais comprida que

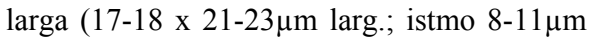
larg.). Esta variedade difere da típica da espécie pelas menores dimensões celulares e pela margem apical reta.

Distribuição geográfica no estado do Amazonas: lago Novo Andirá (primeira citação da ocorrência da variedade).

Material examinado: SP239181, SP239222.

Staurastrum disputatum West \& West var. sinense (Lütkemüller) West \& West Monogr. Brit. Desm. 4: 176, pl. 126, fig. 19. 1912. (Fig. 114-116).

Célula 1,2-1,3 vezes mais comprida 
que larga, sem considerar os processos (18-22 x $13-17 \mu \mathrm{m} ; 22-27 \mu \mathrm{m}$ larg. com processos, istmo 9-10 $\mu \mathrm{m}$ larg.), semicélula obtrapeziforme, 4 processos curtos, cilíndricos, extremidades arredondadas, margens serreadas, 4-5 anéis de pequenos grânulos; vista apical da célula quadrangular, ângulos estendidos em 4 processos, margens côncavas, lisas entre os processos.

Distribuição geográfica no estado do Amazonas: lago Novo Andirá (primeira citação da ocorrência da espécie).

Material examinado: SP239217, SP239218, SP239221.

Staurastrum punctulatum (Brébisson) Ralfs var. punctulatum f. punctulatum Brit. Desm. 133, pl. 22, fig. 1. 1848. (Fig. 117).

Célula 1-1,1 vezes mais comprida que larga (28-31 x 27-30 $\mu \mathrm{m}$; istmo $9-10 \mu \mathrm{m}$ larg.), semicélula transversalmente elíptica, parede celular uniformente granulosa, grânulos concêntricos; vista apical da célula triangular, ângulos arredondados, margens serreadas, ligeiramente retusas entre os ângulos.

Distribuição geográfica no estado do Amazonas: lago Novo Andirá (primeira citação da ocorrência da espécie).

Material examinado: SP239182, SP239183.

Staurastrum quadrangulare (Brébisson) Ralfs var. quadrangulare Brit. Desm. 128, pl. 22, fig. 7, pl. 34, fig. 11. 1848.

(Fig. 118).

Célula 0,9-1 vez mais comprida que larga, sem considerar os processos (18-20 x 19$20 \mu \mathrm{m} ; 24-30 \mu \mathrm{m}$ com processos; istmo $8-10 \mu \mathrm{m}$ larg.), semicélula sub-retangular, parede celular lisa; vista apical da célula quadrangular, ângulos truncados, emarginados, 2 pares de espinhos superpostos, margens côncavas e lisas entre os ângulos.

Distribuição geográfica no estado do Amazonas: lago Novo Andirá (primeira citação da ocorrência da variedade típica).

Material examinado: SP239181.

Staurastrum quadrangulare (Brébisson) Ralfs var. contectum (Turner) Grönblad Acta Soc. Sci. fenn.: sér. B, 2(6): 29, fig. 255. 1945. (Fig. 119-120).
Célula 1-1,4 vezes mais comprida que larga, sem considerar os processos (20-27 x 14$26 \mu \mathrm{m} ; 20-23 \mu \mathrm{m}$ larg. com processos; istmo 9$15 \mu \mathrm{m}$ larg.). A presente variedade difere da típica da espécie pelo maior comprimento celular, pela semicélua obtrapeziforme a subcuneiforme e pela vista apical da célula retangular.

Distribuição geográfica no estado do Amazonas: região de Nhamundá e Terra Santa (Thomasson 1977).

Material examinado: SP239181.

Comentários: Há certa confusão na literatura no que se refere às circunscrições de Staurastrum quadrangulare Brébisson ex Ralfs var. quadrangulare e de $S$. quadrangulare Brébisson ex Ralfs var. contectum (Turner) Grönblad devido, principalmente, à forma da semicélula nesta última ser extremamente variável, o que levou alguns autores a considerar a var. contectum sinônimo da típica e outros a separá-las como espécies distintas.

Staurastrum quadricornutum Roy \& Bisset J. Bot., 24: 240, pl. 268, fig. 4. 1886. (Fig. 121-122).

Célula ca. 1,2 vezes mais comprida que larga, sem considerar os processos (18-20 x 12$16 \mu \mathrm{m}$; ca. 25 x 20-25 $\mu \mathrm{m}$ com processos; istmo ca. $8 \mu \mathrm{m}$ larg.), semicélula sub-retangular a subelíptica, parede celular lisa; vista apical da célula triangular, ângulos com processos 2furcados, cada bifurcação afilando em pequeno processo de extremidade 2-partida, espinhos superpostos, margens laterais côncavas entre os ângulos.

Distribuição geográfica no estado do Amazonas: lago Novo Andirá (primeira citação da ocorrência da espécie).

Material examinado: SP239181.

Staurastrum minnesotense Wolle var. minnesotense Bull. Torrey bot. Club, 12(1): 6, pl. 47, fig. 7-8. 1885. (Fig. 123-1 24).

Célula 1-1,1 vezes mais comprida que larga, sem considerar os espinhos (88-92 x 80$85 \mu \mathrm{m} ; 105-115 \mu \mathrm{m}$ larg. com espinhos; istmo $15-28 \mu \mathrm{m}$ larg.), semicélula transversalmente elíptica, ângulos arredondados, 2 espinhos longos, robustos, 

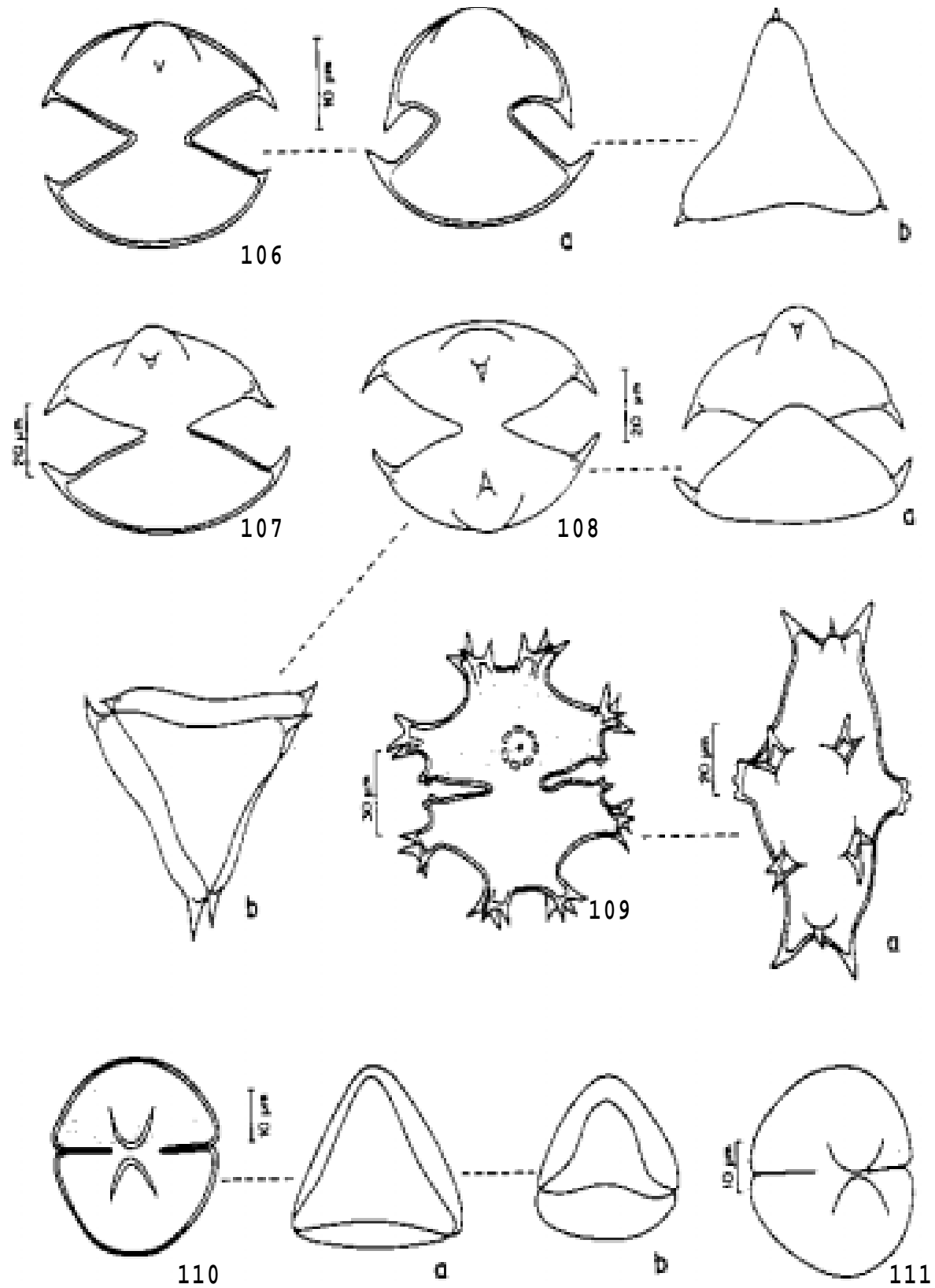

Figura 106. Staurodesmus dickiei var. dickiei; a: diferente expressão morfológica; b: vista apical. Fig. 107-108. S. dickiei var. maximus; a: diferente expressão morfológica; b: vista apical. Fig. 109. Xanthidium trilobum; a: vista lateral. Fig. 110-111. Staurastrum orbiculare var. orbiculare f. orbiculare; a-b: vista apical. 


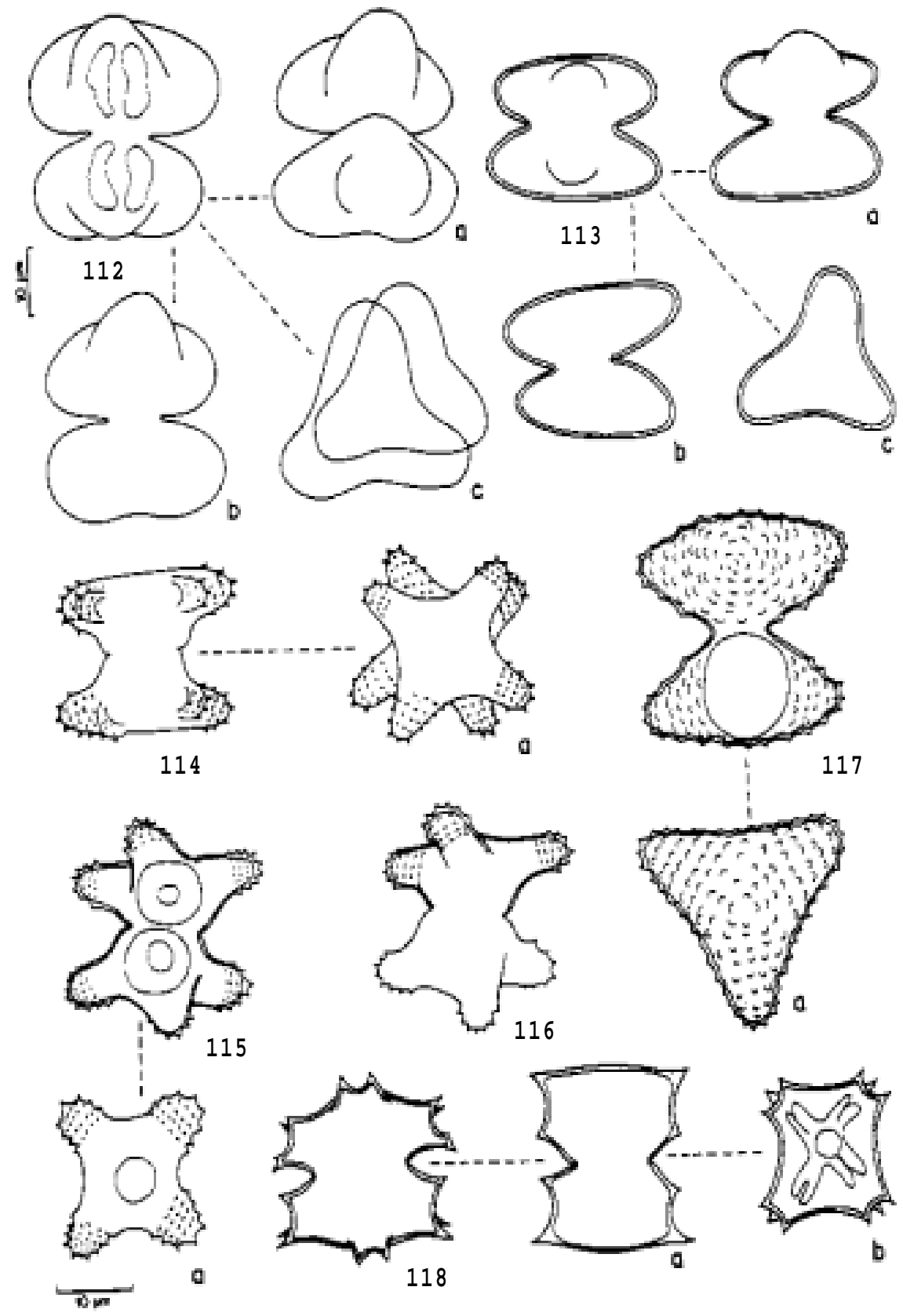

Figura 112. Staurastrum muticum var. muticum; a-b: diferentes expressões morfológicas; c: vista apical. Fig. 113. S. muticum var. depressum; a-b: diferentes expressões morfológicas; c: vista apical. Fig. 114-116. S. disputatum var. sinense; a: vista apical. Fig. 117. S. punctulatum var. punctulatum f. punctulatum; a: vista apical. Fig. 118. S. quadrangulare var. quadrangulare; a: vista lateral; b: vista apical. 

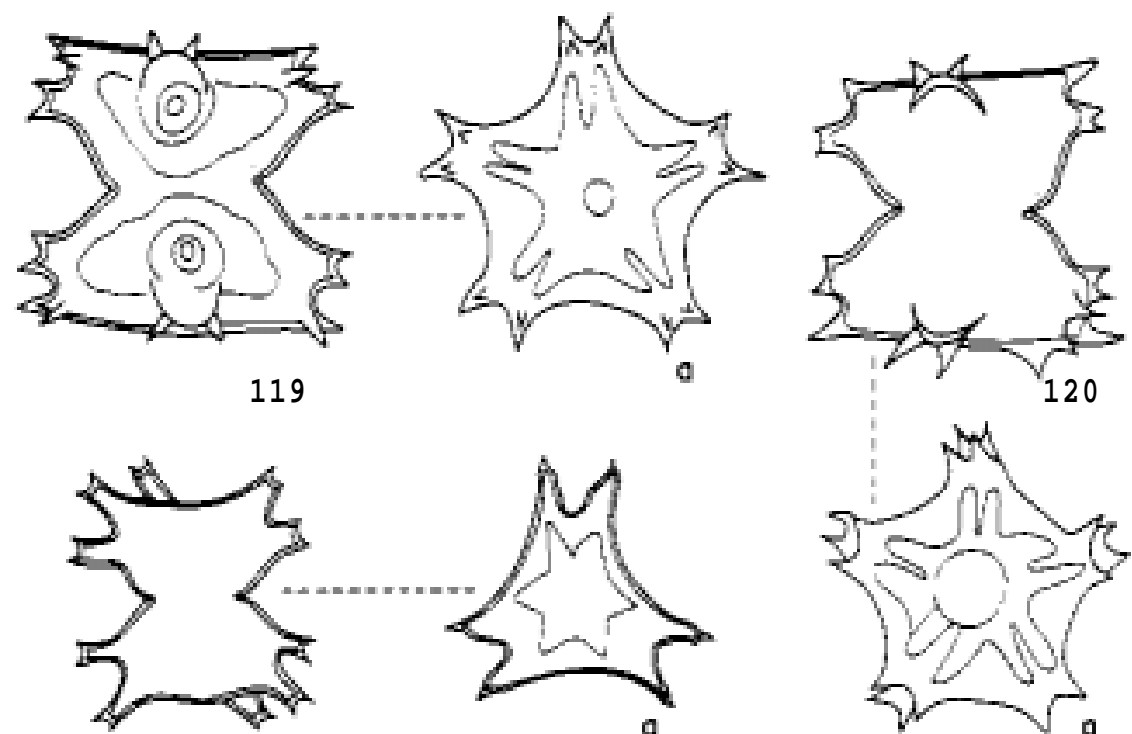

121
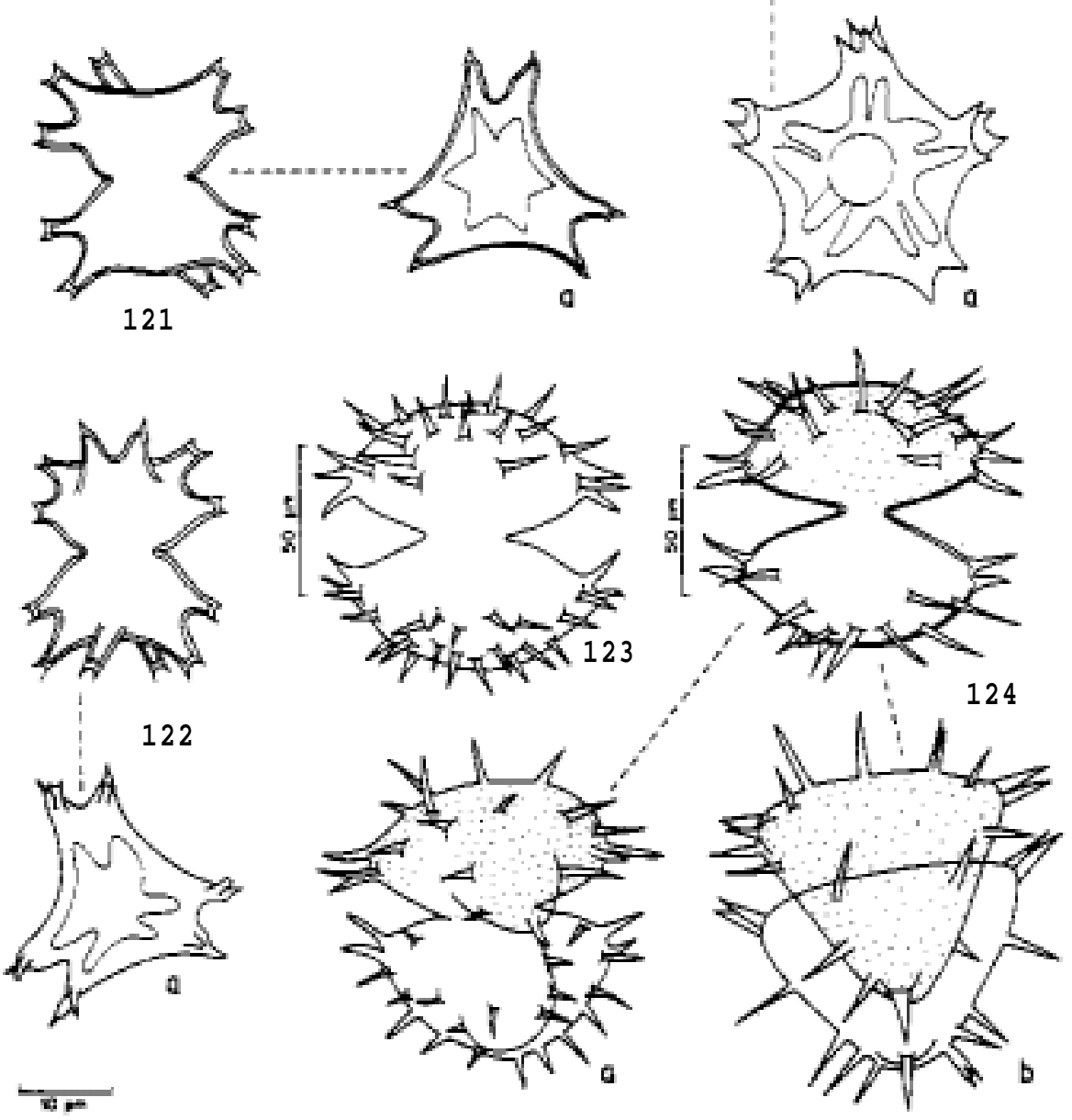

Figura 119-120. Staurastrum quadrangulare var. contectum; a: vista apical. Fig. 121-122. S. quadricornutum; a: vista apical. Fig. 123-124. S. minnesotense var. minnesotense; a: diferente expressão morfológica; b: vista apical. 
ligeiramente voltados para a semicélula oposta; vista apical da célula triangular, ângulos arredondados, 1 par de espinhos longos, robustos, superpostos, margens entre os processos retas, com espinhos longos.

Distribuição geográfica no estado do Amazonas: lago Novo Andirá (primeira citação da ocorrência da espécie).

Material examinado: SP239192, SP239198, SP239204, SP239206, SP239208, SP239210, SP239215, SP239216, SP239219.

Staurastrum trifidum Nordstedt var. inflexum West \& West Trans. Linn. Soc. Lond. Bot.: sér. 2, 5(6): 258, pl. 16, fig. 22. 1896. (Fig. 125).

Célula 1-1,2 vezes mais comprida que larga, sem considerar os espinhos (31-33 x 26-31 $\mu \mathrm{m}$; 38-42 $\mu \mathrm{m}$ larg. com espinhos; istmo $10-12 \mu \mathrm{m} \quad$ larg.), semicélula subcuneiforme, parede celular lisa; vista apical da célula 3-angular, margens levemente côncavas, às vezes retas, ângulos com 3 espinhos curtos, robustos, 1 superior e 2 inferiores.

Distribuição geográfica no estado do Amazonas: reservatório de Balbina (Bittencourt-Oliveira 1993c), região de Nhamundá e Terra Santa (Thomasson 1977), rio Negro (Uherkovich \& Rai 1979).

Material examinado: SP239181.

Staurastrum curvimarginatum Scott \& Grönblad Acta Soc. Sci. fenn.: sér. B, 2(8): 34, pl. 19, fig. 16. 1957. (Fig. 126-129).

Célula 0,9-1 vez mais comprida que larga, sem considerar os espinhos (35-50 x $40-50 \mu \mathrm{m} ; 46-59 \mu \mathrm{m}$ larg. com espinhos; istmo 12-16 $\mu \mathrm{m}$ larg.), semicélula obtrapeziforme, ângulos apicais projetados horizontalmente, 2 espinhos curtos, divergentes; superpostos; vista apical da célula triangular, margens ligeiramente côncavas, ângulos com espinhos superpostos.

Distribuição geográfica no estado do Amazonas: lago Novo Andirá (primeira citação da ocorrência da espécie).

Material examinado: SP239181 e SP239182.
Staurastrum subpolymorphum Borge Ark. Bot., 1: 107, pl. 4, fig. 13. 1903. (Fig. 130).

Célula 1,4-1,7 vezes mais comprida que larga, sem considerar os processos (29-35 x 18$24 \mu \mathrm{m} ; 34-51 \mu \mathrm{m}$ larg. com processos; istmo 10 $12 \mu \mathrm{m}$ larg.), semicélula obtrapeziforme, parede celular lisa; vista apical da célula 6-angular, ângulos estendidos em 6 processos curtos, truncados, extremidades 3-denticuladas, margens lisas, côncavas entre os processos, ornados com 3 pares de diminutos grânulos intramarginais.

Distribuição geográfica no estado do Amazonas: lago Novo Andirá (primeira citação da ocorrência da espécie).

Material examinado: SP239182, SP239183.

Staurastrum margaritaceum (Ehrenberg) Ralfs var. margaritaceum Brit. Desm. 134, pl. 21, fig. 9. 1848. (Fig. 131-133).

Célula 1,4-2 vezes mais comprida que larga, sem considerar os processos (25-31 x $15-21 \mu \mathrm{m} ; 27-50 \mu \mathrm{m}$ larg. com processos; istmo $8-13 \mu \mathrm{m}$ larg.), semicélula obtrapeziforme a transversalmente elíptica, 6 processos robustos, longos, truncados, dirigidos horizontalmente, às vezes 4 deles ligeiramente voltados para o ápice, margens serreadas, extremidades lisas ou 3-denticuladas, 4-5 grânulos; vista apical da célula 6-angular, ângulos estendidos em processos, margens entre os processos retusas, lisas.

Distribuição geográfica no estado do Amazonas: lago Novo Andirá (primeira citação da ocorrência da espécie).

Material examinado: SP239181, SP239182, SP239183, SP239184.

Staurastrum tetracerum (Kützing) Ralfs var. tetracerum f. trigona Lundell Nova Acta R. Soc. Scient. upsal.: sér. 3, 8: 69. 1871. (Fig. 134-137).

Célula 1,1-2 vezes mais comprida que larga, sem considerar os processos (16-27 x 12$19 \mu \mathrm{m} ; 30-50 \mu \mathrm{m}$ larg. com processos; istmo 7$9 \mu \mathrm{m}$ larg.), semicélula obtrapeziforme, parede celular com grânulos restritos aos processos; vista apical da célula 3-angular, cada ângulo com 
1 processo, margens retusas, serreadas entre os processos.

Distribuição geográfica no estado do Amazonas: lago Novo Andirá (primeira citação da ocorrência da forma).

Material examinado: SP239181, SP239182, SP239184.

Staurastrum volans West \& West var. fuquenense Coesel Caldasia, 14(68-70): 408, fig. 2a-e, 3. 1986. (Fig. 138-141).

Célula 1,6-2 vezes mais comprida que larga, sem considerar os processos (17,5-28 x $9,6-15 \mu \mathrm{m} ; 34-68 \mu \mathrm{m}$ larg. com processos; istmo 5-9 $\mu \mathrm{m}$ larg.), semicélula ciatiforme a subcircular, parede celular lisa; vista apical da célula 2-3radiada, corpo celular globoso, quase circular, às vezes subelíptico em indivíduos 2-radiados.

Distribuição geográfica no estado do Amazonas: lago Novo Andirá (primeira citação da ocorrência da espécie).

Material examinado: SP239181, SP239182, SP239183, SP239184.

Comentários: As formas birradiadas da espécie podem ser confundidas com a forma típica de Staurastrum americanum (West \& West) G.M. Smith, se considerarmos que a principal diferença entre ambas é a vista apical da célula elíptica em $S$. americanum e globosa, quase circular, em S. volans. Contudo, é muito difícil separar as duas espécies se indivíduos trirradiados de ambas as populações forem observados isoladamente, visto que todas as demais características morfológicas se sobrepõem. Processos dirigidos horizontalmente e com maior número de crenulações em $S$. americanum, conforme Rich (1932), são as características usadas para separá-las. No entanto, na população ora estudada estas características também apresentaram plasticidade. Um número maior de crenulações foi claramente observado, sete a nove por processo, porém, a posição variou de obliqüamente voltados para cima, como ocorre em S. volans, a quase horizontais, como em S. americanum. Às vezes, as duas posições ocorreram em semicélulas diferentes de um mesmo indivíduo (Fig. 138).

Variação considerável no comprimento dos processos angulares no gênero Staurastrum é um fato corriqueiro em populações de S. margaritaceum (Ehrenberg) Ralfs var. margaritaceum, S. rotula Nordstedt e S. tetracerum (Kützing) Ralfs var. tetracerum f. trigona Lundell e foi observada nas populações que tivemos ocasião de examinar. Por esta razão, acredita-se que S. glabribrachiatum Förster possa, por um lado, ser considerada uma variedade ou forma taxonômica de S. subpolymorphum Borge, desde que a única diferença entre ambas é justamente o comprimento dos processos; ou, por outro, apenas expressões morfológicas distintas de um amplo espectro de variação que englobaria os representantes de ambas variedades acima.

Staurastrum rotula Nordstedt Vidensk. Meddr dansk naturh. Foren., 1869(14-15): 227. 1869 (1870); 1887: pl. 4, fig. 38. 1887. (Fig. 142).

Célula 1,9-2 vezes mais comprida que larga, sem considerar os processos (40-45 x 20$23 \mu \mathrm{m} ; 58-67 \mu \mathrm{m}$ larg. com processos; istmo ca. $11 \mu \mathrm{m}$ larg.), semicélula subelíptica, parede celular com espinhos restritos aos processos; vista apical da célula 8-angular, ângulos estendidos em processos, margens côncavas, lisas entre os processos.

Distribuição geográfica no estado do Amazonas: lago Rio Preto da Eva (Thomasson 1971), rio Maués-assu, rio Maués-mirim, rio Apoquitaua, paraná do Urariá, igarapé Laguinho (rio Maués-assu), lago do Elias (rio Paraconi) (Förster (1974), lago Cristalino, lago São Sebastião (Martins 1986a), lago do Castanho (Uherkovich \& Schmidt 1974), região de Nhamundá e Terra Santa (Thomasson 1977), rio Negro, rio Unini (Uherkovich \& Rai 1979), rio Içá, o Içana, lago Calado (Uherkovich 1981).

Material examinado: SP239181. 

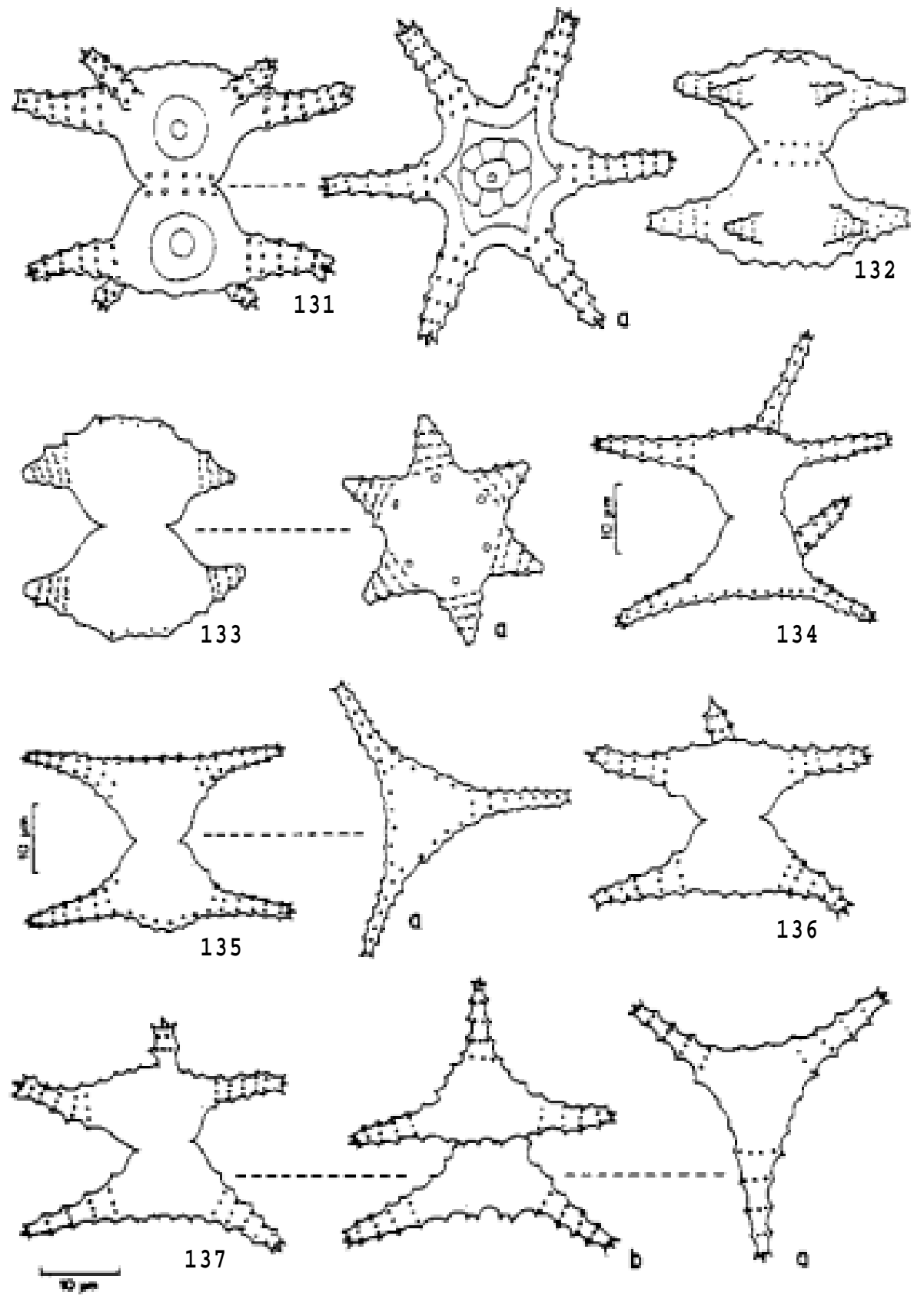

Figura 125. Staurastrum trifidum var. inflexum; a: diferente expressão morfológica; b-c: vista apical. Fig. 126-129. S. curvimarginatum; a: vista apical. Fig. 130. S. subpolymorphum; a: vista apical. 

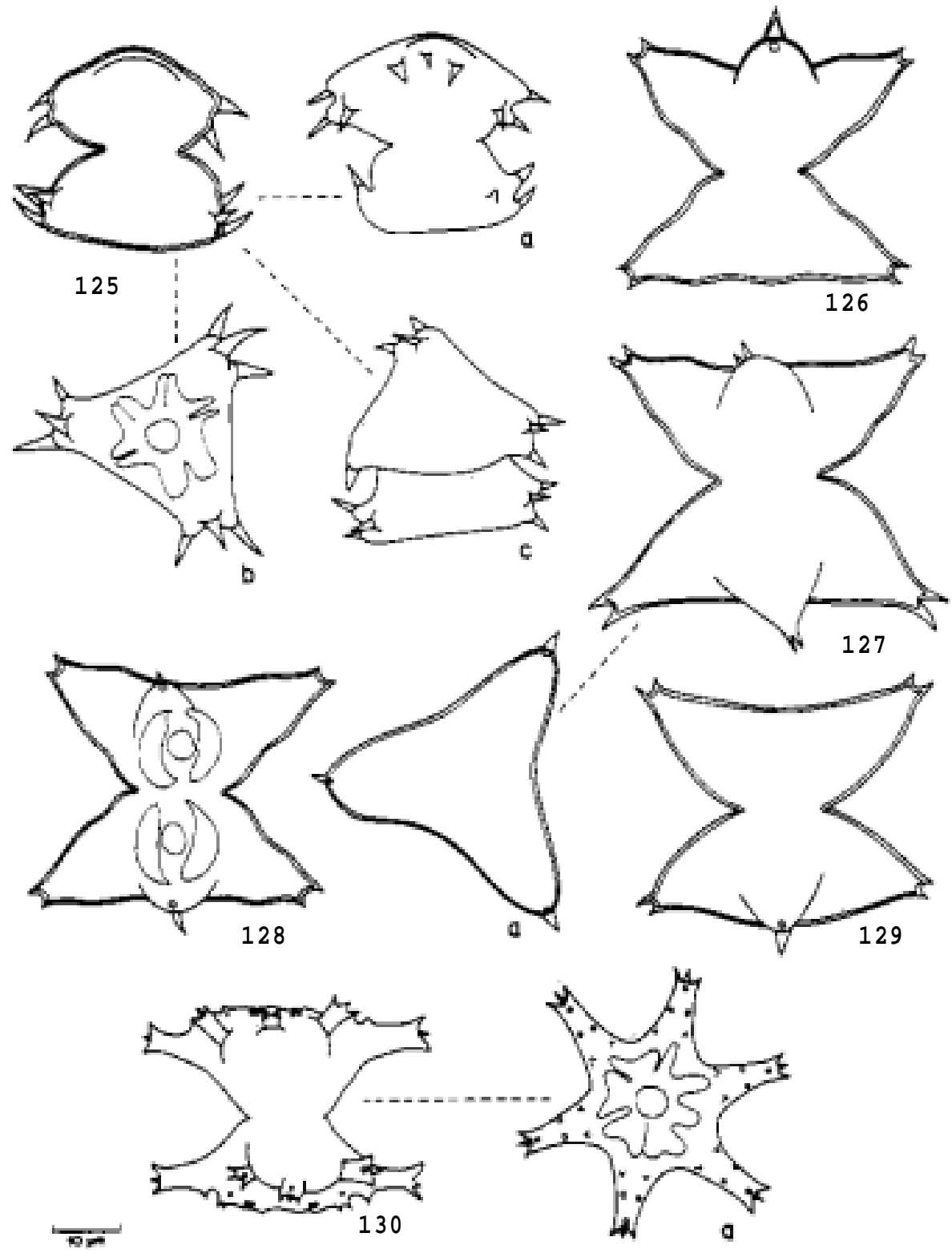

Figura 131-133. Staurastrum margaritaceum var. margaritaceum; a: vista apical. Fig. 134-137. S. tetracerum var. tetracerum f. trigona; a: vista apical; b: diferente expressão morfológica. 

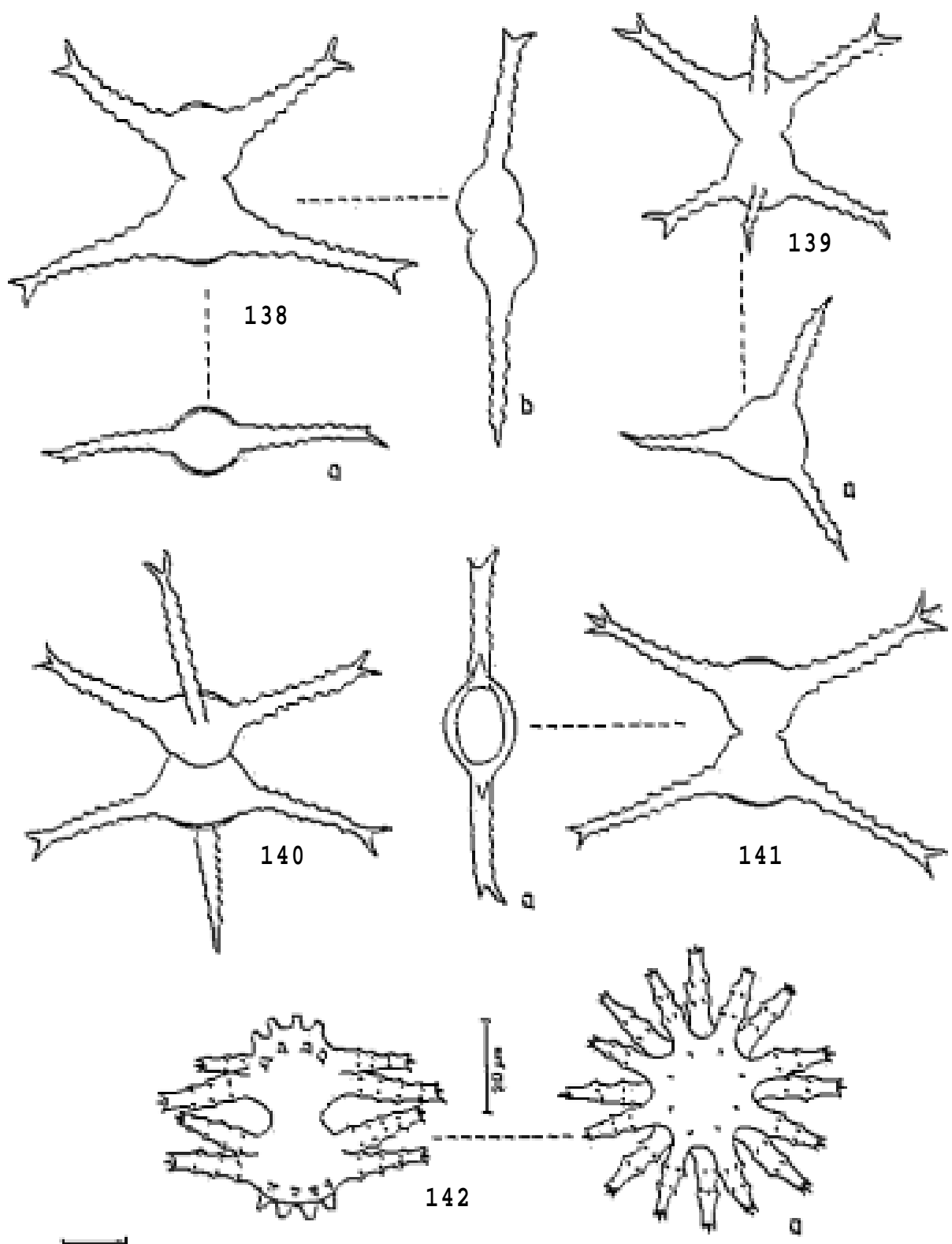

Figura 138-141. Staurastrum volans var. fuquenense; a: vista apical; b: vista lateral. Fig. 142. S. rotula; a: vista apical. 


\section{BIBLIOGRAFIA CITADA}

Bicudo, C.E.M. \& Bicudo R.M.T. 1970. Algas de águas continentais brasileiras: chave ilustrada para identificação de gêneros. Editora Universidade de São Paulo, São Paulo. 228p.

Bicudo, C.E.M. 1986. Ichthyocercus manauensis, a new desmid (Zygnemaphyceae) from Northern Brazil. Amazoniana 9(4): 637-640.

Bittencourt-Oliveira, M.C. 1990. Tetraplektron deniseae: a new specie of Tribophyceae from Amazonas State, Brazil. Hoehnea 17(2): 99-102.

Bittencourt-Oliveira, M.C. 1993a. Ficoflórula do Reservatório de Balbina, Estado do Amazonas, 1: Chlorococcales (Chlorophyceae). Revista Brasileira de Biologia 53(1): 113-129.

Bittencourt-Oliveira, M.C. 1993b. Ficoflórula do Reservatório de Balbina, Estado do Amazonas, 2: Ulothrichales e Volvocales (Chlorophyceae) e classe Oedogoniophyceae. Revista Brasileira de Biologia 53(3): 469-475.

Bittencourt-Oliveira, M.C. 1993c. Ficoflórula do Reservatório de Balbina, Estado do Amazonas, 3: classe Zygnemaphyceae. Revista Brasileira de Biologia 53(3): 477488.

Bittencourt-Oliveira, M.C. 1994. Ficoflórula do Reservatório de Balbina, Estado do Amazonas, Brasil: Nostocophyceae, Cryptophyceae e Tribophyceae. Hoehnea 21(1-2): 163-173.

Bittencourt-Oliveira, M.C. 1995. Ficoflórula do Reservatório de Balbina, Estado do Amazonas, Brasil: Bacillariophyceae e Chrysophyceae. Hoehnea 22(1-2): 147157.

Bittencourt-Oliveira, M.C. 1997. Euglenophyceae do Reservatório de Balbina, Estado do Amazonas, Brasil. Hoehnea 24(1): 21-35.

Bourrelly, P.C. 1972. Les algues d'eau douce: initiation à la systématique, 1: les algues vertes. Éditions N. Boubée, Paris. 572p.

Castro, A.A.J. 1987. O gênero Closterium
(Zygnemaphyceae) no estado de São Paulo: levantamento florístico. Dissertação de Mestrado. Universidade Estadual Paulista, Rio Claro, São Paulo. 235p.

Coesel, P.F.M. 1983. De Desmidiaceeën van Nederland, 2: Fam. Closteriaceae. Wetenschappelijke mededelingen $K$. nederlandse natuurhistorische vereniging 157: 1-49.

Conforti, V.T.D. 1993a. Study of the Euglenophyta from Camaleão lake (Manaus-Brasil), 1: Trachelomonas Ehr. Revue d'hydrobiologie tropicale 26(1): 3-18.

Conforti, V.T.D. 1993b. Study of the Euglenophyta from Camaleão lake (Manaus-Brasil), 2: Strombomonas Defl. Revue d'hydrobiologie tropicale 26(3): 187-197).

Conforti, V.T.D. 1994. Study of the Euglenophyta from Camaleão lake (Manaus-Brasil), 3: Euglena Ehr., Lepocinclis Perty, Phacus Duj. Revue d'hydrobiologie tropicale 27(1): 3-21.

Croasdale, H. \& Flint, E.A. 1988. Flora of New Zealand: freshwater algae, Chlorophyta, desmids, with ecological comments on their habitats. Vol. 2. DSIR, Botany Division, Christchurch. 147p.

Cronberg, G. 1989. Biogeographycal studies scaled ChrysSophytes from the tropics. Nova Hedwigia 95: 191-232.

De-Lamonica-Freire, E.M. 1985. Desmidioflórula da Estação Ecológica da Ilha de Taiamã, Município de Cáceres, Mato Grosso, Brasil. Tese de Doutorado. Universidade de São Paulo, São Paulo. $538 \mathrm{p}$.

Dickie, G. 1881. Notes on the algae from the Amazons and its tributaries. Journal of the Linnean Society of London: sér. bot. 18(108): 123-132.

Drouet, F. 1938. The Brazilian Myxophyceae, 2. American Journal of Botany 25: 657666.

Ehrenberg, C.G. 1841 Verbreitung und Einfluss des mikroskopischen Lebens in Süd und Nord-Amerika. Königlichen Preussischen Akademie der Wissenschaften 1843: 1-158. (1843). 
Förster, K. 1963. Desmidiaceen aus Brasilien, 1: Nord-Brasilien. Revue Algologique: nov. sér. 7(1): 38-92.

Förster, K. 1964. Desmidiaceen aus Brasilien, 2: Bahia, Goyaz, Piauhy und NordBrasilien. Hydrobiologia 23 (3-4): 321505.

Förster, K. 1974. Amazonische Desmidiaceen, 2: Areal Maués-Abacaxis. Amazoniana 5(2): 135-242.

Fukushima, H. \& Xavier, M.B. 1988. Attached diatom from Negro River, Amazonas, Brasil. Diatom Research 4: 11-16.

Gessner, F. \& Kolbe, R. 1934. Ein Beitrag zur kenntnis de Algenflora des unteren Amazonas. Berichte der Deutschen Botanischen Gesellschaft 52(3): 162-169.

Heimans, J. 1946. On closteriometry. Biologisch Jaarboek 13: 146-154.

Hustedt, F. 1952a. Neue und wening bekannte Diatomeen, 3: phylogenetische Variation bei den raphidioiden Diatomeen. Berichte der Deutschen Botanischen Gesellschaft 65(5): 133-144.

Hustedt, F. 1952b. Neue und wening bekannte Diatomeen, 4: Botanische Natur 366-410.

Kammerer, G. 1938. Volvocalen und Protococcalen aus dem unteren Amazonasgebiet. Sitzungsberichte der Akademie der Wissenschaften Wien: sér. math. 147(5-10): 183-228.

Karling, J. 1944. Brazilian chytridis, 4: species of Rozella. Mycologia 36(6): 638-647.

Martins, D.V. 1980a. Desmidioflórula dos lagos Cristalino e São Sebastião, Estado do Amazonas. Tese de Doutorado. Instituto Nacional de Pesquisas da Amazônia/Fundação Universidade do Amazonas, Manaus, Amazonas. 248p.

Martins, D.V. 1980b. Contribuição à ficologia da Amazônia, 2: desmidioflórula dos lagos Cristalino e São Sebastião, Estado do Amazonas: gêneros filamentosos. Acta Amazonica 10(4): 725-741.

Martins, D.V. 1982. Contribuição à ficologia da Amazônia, 3: desmidioflórula dos lagos Cristalino e São Sebastião, Estado do Amazonas: gêneros Netrium, Closterium e Pleurotaenium. Acta Amazonica 12(2): 279-290.
Martins, D.V. 1986a. Staurastrum Meyen (Desmidiaceae) dos lagos Cristalino e São Sebastião, Estado do Amazonas, Brasil. Universitas (Ciência) 36: 15-32.

Martins, D.V. 1986b. Gêneros Euastrum Ehrenberg, Micrasterias Agardh e Triploceras Bailey (Desmidiaceae) dos lagos Cristalino e São Sebastião, Estado do Amazonas, Brasil. Universitas (Ciência) 38: 43-58.

Menezes, M., Fonseca, C.G. \& Nascimento, E.P. 1995. Algas de três ambientes de águas claras de município de Parintins, Estado do Amazonas, Brasil: Euglenophyceae e Dinophyceae. Hoehnea 22(1-2): 1-15.

Mix, M. 1972. Die Feinstruktur de Zellwände bei Mesotaeniaceae und Gonatozygaceae mit einer vergleichender Betrachtung der Conjugatophyceae und über deren systematischen Wert. Archiv für Mikrobiologie 81: 197-220.

Möbius, M. 1892. Ueber einige brasilianische Algen. Berichte der Deutschen Botanischen Gesellschaft 10: 17-26.

NecchiJúnior, O. \& Zuchi, M.R. 1995. Ocurrence of Ballia (Ceramiaceae, Rhodophyta) in freshwater in Brazil. Hoehnea 22(1-2): 229-235.

Palamar-Mordvintseva, G. \& Tsarenko, P.M. 1990. A supplement to the flora algal of the Amazon river basin (Brasil). Ukranian Journal of Botany 47(6): 31-40.

Prescott, G.W., Croasdale, H.T., Vinyard, W.C. \& Bicudo, C.E.M. 1981. A synopsis of North American Desmids, 2(3). Desmidiaceae: Placodermae. University of Nebraska Press, Lincoln, USA. 720p.

Rich, F. 1932. Contributions to our knowledge of the freshwater algae of Afrika, 10: phytoplankton from South of Afrika pans and valleys. Transactions Royal Society of South Afrika 20(2): 149-188.

Sant'Anna, C.L. \& Martins, D.V. 1982. Chlorococcales (Chlorophyceae) dos lagos Cristalino e São Sebastião, Amazonas, Brasil: taxonomia e aspectos limnológicos. Revista Brasileira de Botânica 5: 67-82.

Schmidt, G.M. 1973. Primary production of phytoplankton in three types of Amazo- 
nian waters, 3 : primary productivity of phytoplankton in a tropical flood-plain lake of central Amazonia, Lago do Castanho, Amazonas, Brasil. Amazoniana 4(4): 379-404.

Schmidt, G.W. \& Uherkovich, G. 1973. Zur Artenfülle des Phytoplanktons in Amazonien. Amazoniana 4(3): 243-252.

Scott, A.M., Grönblad, R. \& Croasdale, H.T. 1965. Desmids from the Amazon Basin, Brazil, collected by Dr. H. Sioli. Acta Botanica Fennica 69: 3-93.

Sioli, H. 1968. Principal biotopes of primary production in the water of Amazonia. In: Misra, R. \& Gopal, B. (Eds.). Proceedings of the Symposium on Recent Advances in Tropical Ecology. The International Society for Tropical Ecology. Varanasi. p. 591-600.

Sophia, M.G. \& Dias, I.C.A. 1996. Algas de três ambientes de águas claras do município de Parintins, Estado do Amazonas, Brasil: Oedoggoniophyceae. Hoehnea 23(2): 59-80.

Stearn, W.T. 1983. Botanical Latin: history, gramar, syntax, terminology and vocabulary. David \& Charles Publishers, Edinburgh. 566p.

Teiling, E. 1967. The desmid genus Staurodesmus: a taxonomic study. Arkiv for Botanik 6(11): 467-691.

Thomasson, K. 1955. Studies on South American fresh-water plankton, 3: plankton from Tierra del Fuego and Valdivia. Acta Horti Gotoburgensis 19: 193-225.

Thomasson, K. 1971. Amazonian algae. Mémoires de l'Institute Royale des Sciences Naturelles de Bélgique 86: 1-57.

Thomasson, K. 1977. Two conspicuous desmids from Amazonas. Botaniska Notiser 130: 41-51.

Uherkovich, G. 1976. Algen aus den Flüssen Rio Negro und Rio Tapajós. Amazoniana 5(4): 465-515.

Uherkovich, G. 1981. Algen aus einigen Gewaessern Amazoniens. Amazoniana 7(2): 191-219.

Uherkovich, G. \& Franken, M. 1980. Aufwuchsalgen aus zentralamazonischen Regenwaldbächen. Amazoniana 7(1): 4979.

Uherkovich, G. \& Rai, H. 1979. Algen aus dem Rio Negro und seinen Nebenflüssen. Amazoniana 6(4): 611-638.

Uherkovich, G. \& Schmidt, G.W. 1974. Phytoplanktontaxa in dem zentralamazonischen Schwemmlandensee, Lago do Castanho. Amazoniana 5(2): 243283.

Zimmermann, C.S.J. 1913. Contribuição para o estudo das diatomáceas dos Estados Unidos do Brasil, 1. Broteria: sér. bot. 11(3): 149-164.

Zimmermann, C.S.J. 1914. Contribuição para o estudo das diatomáceas dos Estados Unidos do Brasil, 2. Broteria: sér. bot. 12(1): 5-12. 
